\title{
ADMINISTRACIÓN O ASIENTO. LA POLÍTICA ESTATAL DE SUMINISTROS MILITARES EN LA MONARQUÍA ESPAÑOLA DEL SIGLO XVIII*
}

\section{Direct Administration or Asiento. The State Military Supply Policy in Eighteenth-Century Spain}

\author{
Rafael TORRES SÁNCHEZ \\ Universidad de Navarra \\ Correo-e: rtorres@unav.es
}

RESUMEN: Uno de los supuestos más utilizados para comprender la construcción del Estado ha sido resolver la pregunta de cómo el Estado resolvió la necesidad de movilizar recursos para la guerra: por administración o por asiento. Así, desde Thompson, se ha relacionado la decadencia del Estado de los Austrias con el tránsito de un sistema de administración a otro de asiento, del mismo modo que el fortalecimiento del Estado de los Borbones se ha vinculado a un mayor protagonismo de la administración frente a los asientos. Nuestro objetivo en este artículo es valorar la realidad histórica de este planteamiento. A partir de los estudios realizados para el siglo XVIII, concluimos que el recurso del Estado de los Borbones a los asientos estuvo más vigente de lo que tradicionalmente se ha pensado. Los casos de suministros analizados muestran que no hubo ninguna evolución lineal en ningún sentido; más bien lo que aparece es una continua fluctuación entre métodos. La razón de este comportamiento es que los límites entre asientos y administración eran menores de lo que se ha sostenido y,

Este trabajo forma parte del Proyecto de Investigación financiado por el Ministerio de Economía y Competitividad, HAR2011-23570. El objetivo es revisar la política de suministros militares de los estados europeos en el siglo XviII desde una óptica de comparación. Sobre las actividades del grupo de investigación «Contractor State Group» veáse www.unav.es/centro/contractorstate/ 
sobre todo, que no obstaculizó el fortalecimiento del Estado y el ejercicio de su autoridad.

Palabras clave: Estado, siglo XVIII, administración, asiento, suministros militares, asentistas.

ABSTRACT: One of the commonest handles on state construction in historical studies is to look at how the state solved its warfare resource mobilisation needs: by direct administration or by asiento (state contract) Thompson, for example, has related the decline of the Hapsburg state to the switch from a direct-administration to asiento system, just as the strength of the Bourbon state has been attributed to a greater role of direct administration over asientos. Our aim in this article is to weigh this approach against the historical evidence. On the basis of studies of the eighteenth century we have concluded that the Bourbon state turned to asientos much more often than past historical research might have suggested. The supply cases analysed show that there was never a strict linear development in any direction, rather a continual fluctuation from one to the other. The reasons for this behaviour is because the limits between asientos and administration were much more blurred than has hitherto been thought and, above all, because it did not balk the strength of the state or the exercising of its authority.

Key words: State, Eighteenth century, Direct administration, Asiento, Military supplies, Asentistas.

\section{1. ¿LA Naturaleza del Estado?}

Para la historiografía española ha resultado complicado abordar el estudio de los suministros militares sin tener presente su relación con la constitución política del Estado. La conocida obra de Irving A. Thompson Guerra y decadencia sigue siendo un referente ineludible ${ }^{1}$. En su excelente y seminal estudio sobre la movilización de recursos para la guerra por los gobiernos de los Austrias (1560-1620) expuso con rotundidad que la evolución del sistema empleado por el Estado para

1. Los autores que han abordado revisiones de los avances realizados en estudios de historia militar, como Luis Ribot, María del Carmen Saavedra, David García Hernán, Enrique Martínez Ruiz, Magdalena de Pazzis o Antonio Espino, insisten en la vigencia y trascendencia de la obra y tesis de Thompson. En su interesante síntesis, Espino señala que en todas esas revisiones «Thompson era el más alabado». EsPino LóPEz, A.: «La historiografía hispana sobre la guerra en la época de los Austrias. Un balance, 1991-2000», Manuscrits, 21 (2003), pp. 161-191, cita en p. 163. 
abastecerse de recursos militares afectó profundamente a la constitución del propio Estado. Para Thompson, la decadencia del Estado durante el tránsito al siglo XVII se puede explicar por la descentralización administrativa que supuso acudir a asentistas privados y oligarquías regionales y locales para lograr los suministros materiales y humanos que necesitaba para la guerra. Su conclusión es clara: «Así, pues, elegir entre administración y asiento era tomar una decisión acerca de la naturaleza misma del estado. En el siglo XVIII esto se reconocía claramente» ${ }^{2}$. Con esta idea, Thompson no solo establecía la dimensión política que tenía el estudio de los suministros militares, sino que también establecía una evolución, por la que la decadencia del Estado se acabó cuando los gobiernos del siglo XVIII fueron conscientes de la trascendencia de recuperar, de nuevo, el nivel de control estatal sobre los suministros militares supuestamente alcanzado en tiempos de Felipe II. De manera que, concluye Thompson, la recuperación de ese control estatal durante el siglo XVIII sería producto de la nueva fortaleza del Estado borbónico y la crisis del setecientos se interpreta como un paréntesis en una dinámica aparentemente irremediable de progresivo aumento del control estatal sobre los suministros militares ${ }^{3}$.

La sugerente tesis de Thompson ofrece un valioso material para reflexionar sobre la relación entre la naturaleza del Estado y los suministros militares, o, lo que es lo mismo, la construcción del Estado y la movilización de recursos para la guerra, pero también implica la limitación de las posibles interpretaciones del papel desempeñado por los suministros militares en el desarrollo español. Una buena prueba de los «peligros» que puede implicar una interpretación finalista la encontramos en la imagen que ofreció Jan Glete del caso español. Pese a que Glete escribió en una época en la que la historiografía había comenzado a superar una interpretación de la relación entre Estado y Guerra dominada hasta entonces por la idea de la «coerción» y dando pasos hacia una valoración más positiva que enfatizaba más la «cooperación y coordinación», su interpretación de la política de suministros militares y la construcción del Estado español fue negativa, precisamente porque consideró que España se alejó del supuesto camino de mayor control estatal. Glete se limitó a quedarse con la conclusión de Thompson de que un supuesto menor control estatal de los suministros militares estuvo unido a su decadencia, algo que le llevaba a presentar el caso español como «diferente» del contexto europeo. En sus palabras: «el declive español fue un caso único entre los

2. Thompson, I. A. A.: Guerra y decadencia, gobierno y administración en la España de los Austrias, 1560-1620. Barcelona, 1981, p. 315.

3. Para Thompson, lo significativo del caso español era que se trataba de una marcha atrás en la tendencia centralizadora e intervencionista del Estado que se daba en el contexto europeo y que ya había sido alcanzada en buena medida con Felipe II: «en muchos sentidos Felipe II, al controlar directamente la maquinaria bélica, había marchado a la cabeza de sus primos europeos», THOMPson, Guerra y decadencia..., p. 344. 
estados europeos que alguna vez desarrollaron un Estado fiscal-militar» ${ }^{4}$. Es decir, de nuevo con Thompson, para Glete España era un Estado fiscal-militar en la época de Felipe II porque supuestamente era capaz de administrar directamente la movilización de sus recursos militares, pero dejó de serlo al perder ese control y tener que entregarlo a los asentistas privados.

Esta dinámica de interpretación encajaba bien con los presupuestos metodológicos desarrollados por científicos sociales para explicar la relación entre construcción del Estado y guerra ${ }^{5}$, pero suscita más dudas cuando los historiadores han descendido a la realidad histórica. David Parrot ha cuestionado este, a su juicio, paradigma, y concluye que el aumento de la actividad bélica, en tamaño y tecnificación, no implicó en la Edad Moderna un irreversiblemente monopolio de las fuerzas y de la movilización de los militares en manos del Estado. Se aleja, pues, de interpretaciones finalistas y sostiene que no hay incompatibilidad entre el crecimiento del poder del Estado y el desarrollo de la participación privada en las esferas militares. A su juicio, la historiografía modernista europea demuestra que la coexistencia fue la norma y, es más, que en esa convivencia pudo llegar a aumentar la autoridad y la capacidad de acción del Estado. Para Parrot las esferas pública y privada no son un juego de suma-cero donde la ganancia de uno debe suponer la pérdida del otro. Lo importante para este profesor es cómo ambas esferas se interrelacionaban en contextos históricos concretos, con resultados imprevisibles y de ningún modo sometidos a una tendencia determinada ${ }^{6}$. La importancia de la tesis de Parrot hacía conveniente incluir sus reflexiones en este informe de la revista Studia Historica ${ }^{7}$.

Seguir pensando que lo esencial en el estudio del suministro militar es analizar la opción entre administración o asiento, porque ayuda a comprender la naturaleza del Estado, es limitarlo y desviar la atención de lo verdaderamente importante para el propio Estado, que era conseguir los suministros. Sin salir de la etapa de los Austrias, los excelentes trabajos de Antonio Jiménez Estrella o Alicia Esteban Estríngana han mostrado con claridad para el caso de la pólvora que en el paso de la administración al asiento no estaba en juego «la naturaleza del Estado», sino el desarrollo económico que sostenía la fortaleza de aquel Estado ${ }^{8}$. Del mismo modo,

4. Glete, J.: War and the State in Early Modern Europe. Spain, the Dutch Republic and Sweden as Fiscal-Military States, 1500-1660. Londres, 2002, p. 29.

5. Una valoración de esta historiografía en Torres Sánchez, R.: «The Triumph of the FiscalMilitary State in the Eighteenth Century. War and Mercantilism» en Torres Sánchez, R.: War, State and Development. Fiscal-Military States in the Eighteenth Century. Pamplona, 2007, pp. 13-44.

6. Parrott, D.: The Business of War: Military Enterprise and Military Revolution in Early Modern Europe. Cambridge, 2012.

7. Véase el artículo de David Parrot en esta revista.

8. Jiménez Estrella, A.: «Asentistas militares y fraude en torno al abastecimiento de pólvora en el reino de Granada (siglo XVI)», Investigaciones históricas: Época moderna y contemporánea, 30, 
para Carla Rahn Phillips, quien analiza con detalle el comienzo de la práctica de contratar a constructores privados la producción de buques para la armada real, se puede llegar incluso a una interpretación totalmente opuesta a la tesis establecida por Thompson, ya que, sostiene, solo cuando el Estado se consideraba fuerte, es decir, capaz de hacer cumplir las ordenanzas y leyes que él mismo daba, es cuando dejó de ir a alquilar o comprar barcos y comenzó a imponer contratos de construcción privados con condiciones precisas, de acuerdo a las necesidades geoestratégicas del Estado. La historiadora norteamericana concluye que solo cuando un Estado está desarrollado es cuando puede convertirse en regulador de la capacidad de producción de otros ${ }^{9}$. Caben, pues, más significados e interpretaciones de las establecidas por Thompson. Por todo ello parece conveniente abordar la cuestión de administración o asiento con un cierto alejamiento de la relación con la naturaleza del Estado o de cualquier paradigma sobre la construcción del Estado.

La conveniencia de este planteamiento se confirma cuando nos adentramos en el siglo XVIII, donde tampoco resulta claro que se cumpla la tesis de Thompson, en la que un nuevo tipo de Estado, ya no supuestamente decadente, protagonizaría la recuperación de la «perdida» administración directa de los suministros militares. La evidencia de una reconstrucción militar del Estado borbónico y del notable esfuerzo estatal por reformar las fuerzas armadas heredadas han resultado pruebas suficientes para que tradicionalmente se sostenga que con un Estado fuerte daría lugar a una relación diferente con los abastecimientos militares. Como afirma Teijeiro, haciéndose eco de una idea muy arraigada «que a los estadistas ilustrados del siglo XviII tenía que repugnarles el sistema (de asientos)» ${ }^{10}$. No obstante, la realidad parece más esquiva y, tras tanta nueva ordenanza, administración, arsenales o fábricas, comenzamos a saber que más bien se escondía un activo mundo de asientos, más intenso de lo admitido habitualmente, y no tan alejado de los intereses y la política del mismo Estado.

\section{Administración O ASIENTO EN El Siglo XVIII}

En 1814 Luis María Salazar, ministro de Marina, escribió una obra en forma de «cartas a un amigo» en la que reflexionaba sobre la historia, características y

2010, pp. 11-30, y Esteban Estríngana, A.: «El suministro de pólvora en el ejército de Flandes. Sobre la gestión directa y delegada del aprovisionamiento militar (siglo XVII)» en GARCía HeRnán, E. y Mafri, D. (eds.): Guerra y Sociedad en la Monarquía Hispánica. Política, Estrategia y Cultura en la Europa Moderna (1500-1700). Madrid, vol. II, 2006, pp. 473-522.

9. Phillips, C. R.: Seis galeones para el rey de España: la defensa imperial a principios del s. XVII. Madrid, 1991.

10. Teijeiro de la Rosa, J. M.: La real hacienda militar de Fernando VII: el cuerpo administrativo militar. Madrid, 1995, p. 44. 
problemas de la Marina española ${ }^{11}$. Entre los aspectos abordados en su «Juicio crítico», a Salazar le preocupó la relación que existía entre los suministros navales y el desarrollo de la economía y sociedad de la Monarquía española, o lo que él llamaba el «Estado» ${ }^{12}$. Esto le llevó a tratar en extenso el problema de cuál había sido la política seguida durante el siglo XviI y qué creía él que era más conveniente para el «Estado» a la hora de conseguir sus suministros militares: administración o asiento. Su conclusión, siempre referida a la Armada, estaba clara: «hablando de los acopios y repuestos de la marina hemos sentado que por regla general es preferible el sistema de asientos al de administración» ${ }^{13}$. Para el ministro Salazar era algo evidente: «cualquier hombre medianamente instruido no podrá de dejar de convenir en la máxima muy trivial de que nunca el rey debe meterse a agricultor, ni fabricante, ni mercader» ${ }^{14}$.

Sin entrar en el pensamiento de Salazar, de lo que nos hablan sus ideas es de que todavía a finales del siglo XviI el «debate» no estaba ni mucho menos cerrado en una dirección. Que una persona de gobierno, con larga experiencia en la gestión política de los abastecimientos militares, cuestionase algunos de los supuestos principios políticos atribuidos al Estado borbónico resulta muy significativo. Creemos que si el «debate» persistía era porque la realidad del siglo xviII fue, precisamente, la coexistencia de ambos sistemas, independientemente de la «naturaleza» del Estado.

Resulta arriesgado adelantar conclusiones, especialmente cuando se hace frente a una potente historiografía que ha sostenido lo contrario, pero creemos que el Estado borbónico, como el de los Austrias, desarrolló su política de abastecimiento militar apoyándose mayoritariamente en los asientos y en intermediarios

11. No contamos con ningún estudio sobre el pensamiento de Luis María Salazar, pero al menos podemos suponer que sus ideas y reflexiones se fundamentaban en una contrastada experiencia como gestor político en el ámbito militar. Este alavés, nacido a mediados del siglo XVIII, se formó en uno de los principales centros de formación de la élite de la Monarquía, el Real Seminario de Vergara. Pariente del influyente marino José de Mazarredo y Salazar, entró en la Armada como guardiamarina en 1775 y participó en las campañas navales hasta la Guerra de la Convención. Tras estos años en el Cuerpo General sus influencias familiares o su inclinación personal le permitieron pasar al Cuerpo del Ministerio. Colaboró en 1791 en la redacción de las nuevas Ordenanzas Generales de la Armada, fue nombrado intendente del departamento de Ferrol, en 1807 intendente general de Marina, en 1812 secretario de Hacienda, y desde 1814 secretario de Marina, cargo en el que con algunas interrupciones se mantuvo hasta finales de la década de 1820, con absolutistas o con liberales, O’DonNELL, H.: «Luis María de Salazar, capitán de navío, ministro de Marina», Cuadernos monográficos del Instituto de Historia y Cultura Naval, 54, (Madrid, 2007), pp. 115-128.

12. Salazar, L. M.: Juicio crítico de la marina militar de España dispuesto en cartas de un amigo a otro. Madrid, 1814, Carta III, Enero 1814, p. 5.

13. Salazar, Juicio crítico... Carta XXV, p. 149.

14. «Reflexiones sobre los acopios y repuestos para el servicio de la marina. Ventajas de los asientos». Carta XXIV, Salazar, Juicio crítico... Carta XXIV, Mayo 1814, p. 120. 
privados. La práctica totalidad de suministros militares fue conseguida en una elevada proporción a través de asientos. La lista de suministros es todavía incompleta y las circunstancias de cada uno de ellos variaban y evolucionaron de forma desigual a lo largo del siglo, pero la constante que comenzamos a tener en todos ellos es siempre la misma: una fluctuación entre métodos de gestión, con mayor presencia de los asientos sobre la administración. A nuestro juicio, lo que hubo tras esta aparente imprecisión es una realidad histórica en la que los límites entre administración y asientos eran menos nítidos de lo que los historiadores hemos supuesto, porque para los coetáneos el problema no estaba entre «público»o "privado", sino en si se conseguía o no el producto demandado y en si la autoridad del rey se fortalecía o no.

Un rápido repaso de los principales suministros militares confirma la convivencia de ambos métodos a lo largo del siglo xviII y la mayor presencia de los asientos. En el principal gasto en suministros militares al Estado, los víveres para las fuerzas armadas, el método de abastecimiento seguido por los Borbones fue el de los asientos ${ }^{15}$. El Estado intentó en diversas ocasiones poner el suministro de víveres en manos de la administración directa. El intento más importante fue en la década de 1730, cuando se encargó a los intendentes la función de directores de provisiones, con la misión de contratar la compra a los productores, su preparación y distribución a la tropa, así como la contabilidad de su gestión, mediante los tesoreros de Ejército. El nuevo sistema apenas funcionó una década y con notables limitaciones, y finalmente, en 1739 el gobierno tuvo que recurrir de nuevo a asentistas particulares ${ }^{16}$. Así se mantuvo hasta finales de siglo, cuando en 1799 se volvió a crear una «Dirección General de Provisiones», dependiente de la Secretaría de Hacienda, pero que también duró unos pocos años porque, como afirma Salazar, «desde aquel mismo punto comenzaron las escaseces, los apuros, la mala calidad de los géneros, los clamores, las quejas, y en suma el desorden absoluto y general de este ramo ${ }^{17}$. Del mismo modo, en el suministro de vestuario a las fuerzas armadas nos encontramos con un predominio abrumador del abastecimiento

15. En tiempos de Carlos III el coste anual medio en víveres para las fuerzas armadas era de 48,5 millones de reales de vellón, véase ToRREs SÁNCHEZ, R.: «Los navarros en la provisión de víveres a la armada española durante el siglo XVIII» en «Volver a la «hora navarra». La contribución Navarra a la construcción de la monarquía española en el siglo XVIII. Pamplona, pp. 213-264, 2009, p. 217.

16. Archivo General de Simancas [en adelante AGS], Dirección General del Tesoro [en adelante DGT], inv. 25, leg. 14. Sobre este intento véase Torres SÁnchez, R.: «Cuando las reglas del juego cambian. Mercados y privilegio en el abastecimiento del ejército español en el siglo XVIII», Revista de Historia Moderna, 20 (2002), pp. 487-511 en pp. 491-494.

17. Salazar, Juicio crítico... Carta XXV. p. 176. El propio Salazar ratifica que «casi todo el siglo pasado estuvo el ramo de víveres por asiento», p. 175. 
por particulares durante todo el siglo ${ }^{18}$. De nuevo, fue en la década de 1730 , con el secretario Patiño, cuando hubo un intento de pasar este suministro a la administración directa, con el resultado similar al apuntando con los víveres ${ }^{19}$. Además de este proyecto, podemos añadir que el Estado pretendió que al menos el suministro del vestuario de los batallones de Marina pasara a ser realizado por el Estado ${ }^{20}$.

Entre los recursos militares suministrados con un predominio claro de los asientos se podría incluir también a los soldados, puesto que plantearon el mismo problema de método de abastecimiento. Como ha venido demostrando con rotundidad Francisco Andújar, el recurso a levas privadas para crear nuevos cuerpos de ejército no fue un patrimonio del siglo xvII, sino que también estuvo muy arraigado durante todo el siglo xviII. La opción de confiar en un sistema de reclutamiento gestionado directamente por el Estado, como eran las quintas y reclutas, fue, a juicio de Andújar, ineficaz e insuficiente, y el Estado borbónico necesitó acudir al sistema de asientos privados para crear los cuerpos militares que requería ${ }^{21}$. Por su parte, Thomas Glesener, ha concluido recientemente que «la preocupación por el carácter "público" del reclutamiento ha ocultado toda una vertiente del sistema que estaba en gran parte asumida por empresarios privados». Una realidad que, a su juicio, la historiografía no ha tenido presente, y ha preferido «oponer los asientos por un lado y las quintas por otro, considerándolos como dos etapas sucesivas de una evolución lineal, es necesario (concluye) restituir las experiencias concretas del quehacer dieciochesco que buscaba nuevas formas de colaboración entre los empresarios, los militares y la administración real» ${ }^{22}$.

En otros suministros tenemos menos certezas, en buena medida porque todavía no se han investigado, pero también se puede ver que incluso cuando parte del suministro pasó a la administración, el recurso a los contratistas particulares

18. Solbes Ferri, S.: «Contracting and Accounting: Spanish Army Expenditure in Wardrobe and the General Treasury Accounts in the Eighteenth Century» en Harding, R. y Solbes, S. (coord.): The Contractor State and Its Implications, 1659-1815. Las Palmas, 2012, pp. 273-293. Véase también su trabajo en esta revista, donde afirma que «El aprovisionamiento del Ejército genera una esquizofrenia permanente en los ministros de la Corona, pues el recurso a asientos de provisión que acabamos de describir realmente funciona y se convierte en fórmula dominante durante todo el siglo».

19. Solbes Ferri, S.: "Contracting and Accounting...", p. 283.

20. Marqués de Castejón a Miguel Múzquiz, Madrid 8-9-1776. Se refiere a la orden de 2-9-1763. En 1777 se volvió al sistema anterior de que cada batallón contratase de su cuenta el vestuario, gasto que se incluiría en la llamada "Gran masa» y que se añadía al presupuesto anual de cada Departamento marítimo. En 1771 había 12 batallones de marina, AGS, Secretaría Superior de Hacienda [en adelante SHS], leg. 50. El gasto provocado al Estado desde 1763 a 1777 en AGS, DGT, inv. 46, leg. 5.

21. Andújar Castillo, F.: El sonido del dinero. Monarquía, ejército y venalidad en la España del siglo XVIII. Madrid, 2004. Véase también su artículo en esta revista.

22. Glesener, T.: «La estatalización del reclutamiento de soldados extranjeros en el siglo XVIII», en García Hurtado, M. R. (ed.): Soldados de la Ilustración. El ejército español en el siglo XVIII. La Coruña, 2012, pp. 237-261, citas en pp. 238 y 239. 
siguió existiendo. Así, por ejemplo, en el abastecimiento de pólvora sabemos que en 1760 se produjeron en España 103.480 arrobas de salitre, de las que el $23 \%$ fueron producidas en «fábricas del Rey» y el resto, el 77\%, en «fábricas de particulares» ${ }^{23}$. En América, el recurso a contratistas particulares pudo ser aún más intenso. En el principal centro de producción, México, el asiento fue el único sistema hasta 1767 , pero el paso a la administración directa fue compatible con la continuación de la demanda del Estado a los contratistas principales, como ocurrió en 1781, cuando la producción estatal resultó insuficiente y hubo que encargar una masiva compra de pólvora ${ }^{24}$, una convivencia que también se dio en España, como muestras las grandes contratas de pólvora con los comerciantes Francisco Cabarrús o Juan Gil Meester ${ }^{25}$.

Los suministros en los que el Estado protagonizó una voluntad más clara de intervención fueron los navales, pero tras el esfuerzo de arsenales y construcción naval se esconde una fuerte presencia de asientos. Durante todo el siglo XviII las anclas fueron adquiridas mayoritariamente por el Estado mediante contratas particulares, aunque hubo varios intentos de pasar a la administración su producción a mediados del siglo $\mathrm{XVIII}^{26}$. La provisión de anclas se contrató por asiento hasta finales de siglo, cuando se creó la fábrica de Marrón en Santander, y entonces fue sobre todo por motivos estratégicos y para evitar los peligros de la proximidad a la frontera francesa. Con todo, la gestión por administración no llegó a una década, y en 1804 volvió a contratarse por asiento el suministro ${ }^{27}$. Del mismo modo, en la provisión de los betunes y brea el abastecimiento de la Armada se hizo exclusivamente por asentistas. Pese a que llegaron a funcionar durante varios años hasta tres fábricas de betunes por administración para suministro naval, el Estado dependió de contratos privados para asegurar este abastecimiento ${ }^{28}$. Aún más claro fue el recurso a asientos en la provisión de herrajes y clavos. La existencia de fraguas en los arsenales no limitó la completa dependencia del Estado

23. El salitre componía el $75 \%$ de la pólvora, García-Torralba Pérez, E.: La Artillería Naval Española en el Siglo XVIII. Madrid, 2010, p. 572.

24. Villar Ortiz, C.: La renta de la pólvora en Nueva España (1569-1767), Sevilla, 1988; NúñEZ Torrado, M.: «Estudios de costes en la renta de la pólvora de nueva España ante la implantación de un nuevo sistema de gestión (1766-1785)», Revista española de financiación y contabilidad, 111 (2002), pp. 47-74.

25. Contrata con la casa Cabarrus y Lalanne, 1779 en AGS, SSH, leg. 1048. Con Juan Gil de Meester (de Amsterdam) en 1-1-1780 en Archivo Histórico Nacional, Hacienda, libro 6731. Con Meester el Estado también había contratado la provisión de pólvora en 1776, AGS, SSH, leg. 269.

26. Analizamos esta cuestión en Torres SÁnchez, R.: «Producir o comprar, la demanda de la corona española de productos industriales en el siglo XVIII» en Rıвот L. A. y Rosa, L. de: Industria y Época Moderna. Madrid, 2000, pp. 95-131, pp. 118-123.

27. Merino, J. P.: La Armada española en el siglo XVIII. Madrid, 1981, p. 99.

28. Merino: La Armada española... pp. 281-286. Véase también Torres SÁnchez, R.: La llave de todos los tesoros. La Tesorería General de Carlos III. Madrid, 2012, pp. 254-255. 
de productores y comerciantes particulares. En otros productos, como el cáñamo o la madera, la política intervencionista del Estado fue mucho más activa, pero la necesidad de seguir acudiendo a los contratos particulares subsistió y durante la segunda mitad del siglo xviII se impuso como el método mayoritario de abastecimiento ${ }^{29}$. Esta realidad de mayoritario abastecimiento de suministros navales por asiento se reflejó en el modo de financiación, que fue retirado de la gestión de las juntas departamentales en beneficio de la Tesorería General, quien pagaba finalmente a los asentistas navales ${ }^{30}$. Y todos estos asientos, además, daban lugar a una circulación incesante de transportes con suministros por todo el país, en carretas y embarcaciones, cuyo principal medio de contratación era casi siempre por asiento. Como reconocía el ministro Arriaga en el transporte de betunes para la Armada: «se ha cuidado siempre mucho la diligencia de establecer por asiento estas prácticas (de transporte) pues de disponerla por administración no se lograría en todos tiempos puntual y suficiente carruaje, ni con igualdad en precio» ${ }^{31}$. El transporte, en realidad, sería la punta de lanza de un mundo de pequeños asientos, en palabras de Francisco Andújar «microasientos» que con el Estado o entre particulares multiplicarían la trascendencia de los asientos de suministros militares ${ }^{32}$.

La presencia de los asientos fue relevante incluso en el terreno más celosamente controlado por el Estado como fue el armamento y la construcción naval. En cuanto al abastecimiento de armas, González Enciso sostiene que hasta 1760 el sistema de asientos fue el único medio de suministro, y que solo a partir de entonces el peso de la administración directa fue mayoritario ${ }^{33}$. No obstante, en el programa que él mismo denomina «estatalizador» de la producción de armamento, la contribución de los particulares tuvo cierta presencia y, de nuevo, el proceso no

29. Torres SÁnchez, R.: «La política de abastecimiento de cáñamo a la Armada en la segunda mitad del siglo XVIII", Revista de Historia Naval, 116 (2012), pp. 47-71. Véase también el excelente trabajo de DíAz ORdóñez, M.: Amarrados al negocio. Reformismo borbónico y suministro de jarcia para la Armada Real (1675-1751). Madrid, 2010.

30. Torres Sánchez, R.: La llave de todos los tesoros..., p. 237.

31. Cádiz 18-2-1760. AGS, Marina, leg. 609. Esta realidad de un mundo de transportes por asiento estaba presente incluso en las producciones que habían pasado a manos del Estado, como los cañones de bronce de Sevilla. Aguilar Escobar, A.: Cañones de bronce para el Ejército. Historia de la Real Fundición de Sevilla en el siglo XVIII. Madrid, Adalid, Ministerio de Defensa, 2010, p. 168. Un ejemplo de transporte por asiento González Enciso, A.: «La renovación del asiento de transporte de municiones y armas en 1793 y el protagonismo de una familia navarra» en Memoria $y$ Civilización, 15, 2012, pp. 51-69. Véase también la sugerente reflexión en GonZÁLEz ENCISO, A.: «Estado militar y empresarios de industrias militares» en González Enciso, A. (ed.): Un Estado Militar. España, 1650-1820. Madrid, 2012, pp. 423-447.

32. Expresión utilizada en el artículo de Francisco Andújar en esta misma revista.

33. González Enciso, A.: «Del contractor state al Estado fabricante. El cambio de propiedad en la fábrica de municiones de Eugui en 1766», Revista de Historia de la Economía y de la Empresa, BBVA. Madrid, VII, 2013, pp. 455-480. 
fue irreversible. En los cañones, por ejemplo, las dificultades para producir en las fábricas estatales obligaron a realizar compras masivas en el exterior, la provisión de materiales fue siempre mediante contratos y a finales de siglo incluso se volvió a introducir el sistema de asientos con particulares ${ }^{34}$. Aún más importante fue la presencia de asientos en el suministro de armamento ligero, como fusiles, pistolas y espadas, donde el Estado mantuvo durante todo el siglo el recurso mayoritario a los asentistas privados ${ }^{35}$. Algo similar encontramos en la construcción naval. Cuando el profesor Merino comentó el gráfico de navíos construidos durante el siglo xviII hizo un comentario muy revelador: «confieso mi sorpresa ante el resultado del gráfico «navíos» en la primera mitad del siglo xviII» ${ }^{36}$. Su sorpresa se fundaba en el hecho de que el mayor esfuerzo de construcción naval de la primera mitad del siglo no procedía de los nuevos arsenales establecidos por el Estado en la Península, sino de La Habana y Guarnizo y construidos por asientos particulares ${ }^{37}$. Esta idea ha quedado ratificada y ampliada por el estudio de Iván Valdez-Bubnov, quien ha demostrado de forma convincente que en el programa de construcción naval de los Borbones la presencia de la construcción naval por asiento fue muy superior a lo que tradicionalmente se ha planteado, y tampoco aquí se produjo una irremediablemente e irreversible mayor intervención de la administración. Como nos recuerda el propio autor, hacia finales de la década de 1780 se «definía la reintroducción de las contratas y asientos en el sistema naval como una prioridad estratégica, lo cual demuestra que el ideal de la administración directa aparecía menos que rentable ante las altas esferas del gobierno. La documentación conservada por los departamentos navales de la Península, por otra parte, confirma enteramente esta perspectiva» ${ }^{38}$.

34. Un análisis de las consecuencias prácticas del paso a una producción estatal de cañones en Torres SÁnchez, R.: «Velas sin Cañones. La eficacia de las reformas artilleras tras la Guerra de los Siete Años» en Morales Padrón, F. (coord.): Piratería, Corso y Guerra Marítima. XVII Coloquio de Historia Canario-Americana. Las Palmas de Gran Canaria, 2008, pp. 1717-1728. Un ejemplo de la vuelta a los asientos particulares en CARMONA, X.: «Antonio Raimundo Ibáñez, un empresario en el filo de dos épocas» en Ocampo, J.: Empresa y empresarios en el norte de España (Siglo XVIII). Trea, pp. 69-90.

35. Martí, R.: Cataluña armería de los Borbones. Las armas y los armeros de Ripoll, Barcelona, Manresa, Igualada... de 1714 a 1794. Barcelona, 2004, pp. 51-70.

36. Merino: La Armada española..., p. 359.

37. Esta idea ya fue expuesta con rotundidad por María Mestre en un sugerente artículo, que desgraciadamente no ha tenido continuidad. Mestre Prat de Padua, M.: «La construcción naval de guerra en la España del siglo XVIII. El marco legal de los procesos de financiación» en MARTíneZ SHAw, C. (ed.): El derecho y el mar en la España moderna. Granada, 1995, pp. 299-322. Sobre los asientos de construcción en Guarnizo y La Habana véanse: Castanedo Galán, J. M.: Guarnizo, un astillero de la Corona. Madrid, 1993, y Serrano Álvarez, J. M.: El astillero de La Habana y la construcción naval militar (1700-1750). Madrid, 2008.

38. Valdez-Bubnov, I.: Poder naval y modernización del Estado: política de construcción naval española (siglos XVI-XVIII). México, 2011, p. 365. 
Parece razonable concluir que, en el conjunto del siglo xviII, los Borbones emplearon, al igual que los Austrias, los asientos con particulares como el método principal para conseguir los suministros militares, pese a que la «naturaleza» del Estado pudiese haber evolucionado. Lo que nos interesa ahora es explicar las causas de la política de suministros seguida por los Borbones, y por qué no hubo una definición más clara del método a seguir, ya fuese por administración o por asiento.

\section{LA POLÍTICA PRAGMÁTICA}

Creemos que los gobernantes borbónicos actuaron en materia de suministros militares con un marcado sentido pragmático: cualquier método era válido, siempre que sirviese para lograr el objetivo inmediato de la provisión y, al mismo tiempo pero igual de importante, no supusiese una cesión de la autoridad real.

Para el Estado de los Borbones lo esencial fue asegurar que tendría soldados y que estos tuviesen uniformes o sables, el cómo y las consecuencias podía ser muy secundario, de ahí que el incumplimiento en un suministro o el temor al desabastecimiento fuera el principal estímulo para cambiar de método. Numerosos ejemplos muestran la vigencia durante todo el siglo XviII de este orden de prioridades. Así, el nuevo método por administración del suministro de vestuario ordenado en 1763 por el Estado para los batallones de marina tuvo que ser desmontando en 1776 a petición del propio secretario de Marina por «los perjuicios que se siguen a la tropa de los batallones de marina de la practica actual de suministrarla el vestuario por cuenta de la Real Hacienda, por las pérdidas y averías que experimenta en los transportes de mar, y por el atraso con que lo reciben ${ }^{39}$. Nada importó que se estuviese en plena oleada de medidas intervencionistas, lo más importante era asegurar que esa tropa contase con los vestuarios. Del mismo modo, el fracaso de producción de la Real Fábrica de anclas en Rentería en 1749 aconsejó al Estado renunciar a todas las inversiones realizadas y a confiar en el suministro por asiento ${ }^{40}$. La regularidad con la que en adelante la Armada recibió las anclas que necesitó desanimó cualquier nuevo intento de volver a la administración, y el abastecimiento fue asegurado por los que el propio Estado llamaba

39. Castejón a Miguel Múzquiz, Madrid 8-9-1776. Se refiere a la orden de 2-9-1763. En 1777 se volvió al sistema anterior de que cada batallón contratase de su cuenta el vestuario, gasto que se incluirá en la llamada «Gran masa» y que se añadía al presupuesto anual de cada Departamento marítimo. En 1771 momentos había 12 batallones de marina, AGS, SSH, leg. 50. El gasto provocado al Estado desde 1763 a 1777 en AGS, DGT, inv. 46, leg. 5.

40. Las razones de este fracaso en Odriozola Oyarbide, M. L.: «La Real Fábrica de anclas de Renteriola: un intento fallido", Boletín de la Real Sociedad Bascongada de Amigos del País, 46:1-2 (1990), pp. 41-78. 
«Ympresarios de anclas» ${ }^{41}$. En la misma dirección apunta Germán Luis Andrade cuando, al analizar los suministros navales en México concluye: «los fracasos y excesivos gastos que se tuvieron en los casos de los astilleros de La Habana y Coatzacoalcos hicieron que la marina volviera a utilizar el sistema de asientos $»^{42}$. A la misma conclusión se llega cuando se comprueba la reactivación de la construcción naval por asiento en el Cantábrico y La Habana en la primera mitad del siglo xviII, y que no se puede entender sin tener presente la lentitud y fracaso en los planes de construcción de Patiño y Ensenada en los arsenales estatales. Como sostuvo el Intendente General de la Armada Julián Arriaga, ante la lentitud y los problemas en la construcción del arsenal de La Carraca y la imposibilidad de cumplir el programa de construcción naval previsto, «es positivo que los asientos no son buenos, pero los hace precisos la dificultad de exacta administración» ${ }^{43}$.

El fracaso o el desabastecimiento como motor de cambio de método de abastecimiento no iba solo en una única dirección; el fracaso de un asentista era también el principal motivo para volver a una gestión directa. En 1753 el marqués de Ensenada ordenó que el suministro de víveres se hiciese por administración para resolver las dificultades y carencias de la provisión por asiento, y en administración estuvo durante dos años, cuando se volvió a proveerse por asiento ${ }^{44}$. Lo mismo ocurrió diez años después, cuando en una coyuntura de fuerte alza de precios agrícolas, los Cinco Gremios Mayores mostraron su deseo de abandonar la provisión. Entonces la reacción fue la misma, y el Estado ordenó que el suministro se hiciese enteramente «por cuenta de la Real Hacienda», y los Cinco Gremios Mayores actuaran como empleados del Rey. Pasada la crisis agrícola, el Estado volvió al sistema de asientos anterior ${ }^{45}$, y, de nuevo, en la siguiente década, ante los problemas que tenía el Banco de San Carlos para cumplir su suministro de víveres por asiento, el secretario de Hacienda Pedro López de Lerena ordenó cambiar de método «porque si no se rescinde este asiento vendrá a arruinar a los accionistas (del Banco)», y se ajustó con los Cinco Gremios Mayores para que hiciese este suministro, explícitamente, «por administración» ${ }^{46}$.

41. Una relación de estos asientos de anclas en AGS, Marina, leg. 606.

42. Andrade MuÑoz, G. L.: Un mar de intereses. La producción de pertrechos navales en Nueva España, siglo XVIII. México 2006, p. 83.

43. 1752 citado por Baudot Monroy, M.: «Barcos para el Rey. Julián de Arriaga, la madera y la construcción naval (1752-1759)» en García Hurtado, M. R. (ed.): La Armada española en el siglo XVIII. Ciencia, hombres y barcos. Madrid, 2012, pp. 297-328, en p. 316.

44. AGS, DGT, inv. 25, leg. 14. TorRES SÁnCHEZ, R.: «El gran negocio de la época, la provisión de víveres al ejército por Francisco Mendinueta (1744-1763)», en Aquerreta, S. (ed.): Francisco Mendinueta: Finanzas y mecenazgo en la España del siglo XVIII). Pamplona, 2002, pp. 101-134 y 127.

45. El expediente en AGS, SSH, leg. 644.

46. Pedro de Lerena, 3-9-1789, AGS, SSH, leg. 647. El problema se analiza en Torres SÁNchez, R.: «Los Cinco Gremios Mayores y la provisión de víveres al ejército español en el siglo XVIII», Studia Historica. Historia Moderna, 34 (2012), pp. 407-432 y 430. 
Para el Estado parece que la prioridad era que la tropa tuviese su suministro, y con ello estuviese operativa, y el método podía quedar en un segundo plano. En realidad, esta forma de actuar no era muy diferente de la que empleaba Gran Bretaña, donde el fracaso de los proveedores fue el principal motivo para cambiar de sistema de suministro, como ocurrió en la guerra de la Oreja de Jenkins ${ }^{47}$.

\section{El PRECIO POLÍtico}

Tradicionalmente la opción entre administración o asiento se ha interpretado en clave económica, es decir, el motor de cambio era la creencia de que se reduciría el coste, en una u otra dirección. También aquí encontramos indefinición, y nada parecido a la declaración de principios que hizo el Victualling Board cuando se le preguntó expresamente sobre cuál era el medio más económico para abastecer las fuerzas armadas británicas: «no es necesario insistir en el principio general de que el gobierno consigue sus suministros militares más baratos por contrato que si los obtuviera por medio de sus empleados» ${ }^{48}$. La cuestión, de nuevo, es por qué no hubo argumentos claros y mantenidos en el tiempo hacia alguna opción. Creemos que un elemento que pudo contribuir a esa persistente indefinición y dualidad de métodos de abastecimiento fue, precisamente, el precio de los suministros, o más concretamente la falta de un precio económico, o si se prefiere, la existencia de un significado político concedido por Estado y asentistas al precio, que no tiene que ver estrictamente con las reglas del mercado.

A partir de los procesos de negociación seguidos en algunos asientos podemos establecer que el precio de los suministros tenía un contenido esencialmente político y no solo económico, como cabría pensar. Al Estado le resultaba muy difícil precisar el precio de los suministros, imprescindible para valorar la conveniencia de un sistema u otro. Cuando el contador general del Consejo de Indias, Tomás Ortíz de Landázuri, exigió en 1772 que se determinase el coste real que tenía para el Estado la producción de la pólvora mexicana que se hacía en las fábricas del rey, la respuesta que recibió fue sorprende: que se calculaba sobre la base de 3 reales la libra, que era «el precio al que el último asentista del ramo vendía la pólvora a

47. Morris, R.: The Foundations of British Maritime Ascendancy. Resources, Logistics and the State, 1755-1815. Cambridge, 2011. Véase también Bannerman, G. E.: Merchants and the Military in Eighteenth-Century: British Army Contracts and Domestic Supply, 1739-1763. Londres, 2008 y KNight, R. y Wilcox, M.: Sustaining the Fleet, 1793-1815. War, the British Navy and the Contractor State. The Boydell Press, Woodbridge, 2010.

48. En el texto original, de octubre de 1814, en cursiva «general principle». Morris, R.: The Foundations of British Maritime..., nota 117, p. 113. Sobre el funcionamiento del Victualling Board, véase Macdonald, J.: Feeding Nelson's Navy. The True Story of Food at Sea in the Georgian Era. Londres, 2006, pp. 45-71. 
la Corona», que a su vez era el mismo precio que el Estado fijó en 1642, precio fijado entonces dentro de una negociación que incluía la gestión de la renta. En este ejemplo, el precio no se determinaba a partir de algo parecido a un análisis del coste del suministro, sino que se basaba en la memoria institucional. Las recomendaciones finales del fiscal fueron la de «no incluirse unos cargos y datas imaginarios por virtud del precio ideal de tres reales», pero ni siquiera eso se llegó a seguir y el precio de la pólvora producida por el Estado a finales del siglo XVIII siguió siendo determinado por el precio de mediados del siglo XvII ${ }^{49}$.

Otros muchos ejemplos nos permiten sostener que el grado de desconocimiento con el que se manejaba el Estado en el terreno del cálculo de costes fue realmente elevado, y parece que los avances en las instituciones de control presupuestario, como fue la Tesorería General, no cambiaron de forma sustancial esta persistente realidad. En una relación detallada del coste que había tenido al Estado la provisión de víveres al ejército desde 1744 a 1757 se pudo establecer con aparente precisión cuánto había costado cada ración de pan y de cebada en cada año que había sido proporcionado por asiento, pero no los dos años, 1753 y 1754, en que «no hubo asiento y corrió por comisión de cuenta de la Real Hacienda y en la Tesorería Mayor no hay noticia del coste que tuvo» ${ }^{50}$. La razón es que la Real Hacienda sabía perfectamente cuánto se abonaba al asentista, pero reconocía que no podía precisar el coste que tenía para la administración porque muchos gastos no se computaban. Lo que había sido un argumento tradicional en defensa de que los suministros pasasen a ser gestionados por el Estado, que la administración no necesitaba sostener una red de corresponsales ya que podía usar la propia administración estatal, en realidad era el mayor obstáculo para controlar el precio de un suministro ${ }^{51}$. Incluso en los suministros mejor fiscalizados, como eran en general los de la Armada y, de forma especial, en la construcción naval, el Estado no logró, pese a que lo intentó en repetidas ocasiones a lo largo del siglo xviII, conocer cuál era el precio final de los suministros, $y$, en concreto, de un buque construido y equipado, según fuese realizado por administración o por asiento. Todavía en 1790 la Secretaría abordó un último estudio de los costes de construcción para decidir «el método que debía emplearse en la construcción de nuevos buques» sin que

49. Las ventajas para la administración de precisar el coste real eran obvias porque «se podría descender el celo al examen de la causa de la alteración», y determinar si es por cambio en los precios de las materias primas, mano de obra, producción, distribución «o por descuido o malversación del Administrador». NúÑEZ TorRado: «Estudios de costes en la renta de la pólvora...», p. 72.

50. AGS, SSH, leg. 641.

51. Como afirmaba Fermín Folch, porque «directores son los Intendentes, por oficiales de cuenta y razón sirven las contadurías principales, tesoreros son los de los Ejércitos, por otros dependientes sirven los comisarios de guerra» Madrid 22-9-1740, Informe de Fermín Buenaventura Folch a Fernando Verdes Montenegro sobre la propuesta de provisión de víveres hecha por Manuel Santos, administrador de la casa del marqués de Valdeolmos, AGS, SSH, leg. 640. 
tampoco entonces fuese algo concluyente, porque la decisión final se basó más en las presiones ejercidas por los propios marinos ${ }^{52}$.

Si el Estado de los Borbones tuvo serias dificultades para conocer el precio de los suministros, no parecen fundamentadas las críticas de despilfarro con las que habitualmente se acusaba a los asentistas. Así, por ejemplo, cuando Gabriel Arrieta escribió su popular Alphabeto y Cartilla Militar criticó abiertamente los métodos de abastecimiento de los asentistas por las «ganancias y utilidades con que se han enriquecido los asentistas», no ofreció datos precisos de cuánta habría podido ser la ganancia ni cuáles podrían ser los beneficios si se hiciera por administración. Lo sorprendente es que para hacer sus especulaciones reconocía que «ha sido preciso, para hacer la regulación de su importe con todo conocimiento, valerse de los asientos ${ }^{53}$. Probablemente muchos de los críticos de los asentistas, en su mayoría administradores del Estado, no se apoyaron en datos precisos de ningún tipo, y argumentaron con el convencimiento de que el dinero pagado por el Estado era un despilfarro de la Real Hacienda. Como resumía el marqués de Castejón, secretario de Marina, haciéndose eco de las quejas y críticas de varios empleados de la Secretaría, «todo es pérdida de la hacienda del Rey y todo ganancia de los asentistas» ${ }^{54}$

Lo que parece claro es que las dificultades del Estado para controlar el precio de los suministros, especialmente cuando estaba en administración, abría el campo para que el precio de los asientos se llenase de contenido político. El Estado solo podía contrastar el precio en función de la memoria institucional, de los precios anteriores, y la decisión final quedaba más bien dentro de un proceso de negociación política. El análisis de los procesos de adjudicación de asientos muestra que el precio final casi nunca estaba determinado por el mercado, y el procedimiento legal establecido de subasta pública en realidad era compatible con la negociación política. En un modesto asiento de tablonería de roble en Navarra los asentistas impusieron la condición de que no se publicasen los precios del asiento puesto que «recela que si este (el asiento) se publica como se quiere, alterarán los dueños (de los árboles) los precios» ${ }^{55}$. El Estado ordenaba a sus representantes en los lugares de subasta que interviniesen e influyesen directamente sobre los postores, antes incluso de que llegasen a la subasta, para acordar previamente un precio. Como le exigía el marqués de Ensenada al ministro de marina de Bilbao en el proceso de adjudicación de un contrato de provisión de clavazón y herraje en 1750 para

52. El estudio se hizo en La Habana en 1792, y la comparación de costos realizados entre ambos sistemas mostró que era más barato por asiento: un $8 \%$ en el navío y un $40 \%$ en la fragata, VALDEZBubnov: Poder NAVAL..., p. 423.

53. Arrieta, G.: Alphabeto y cartilla militar, Cádiz, 1757, referencias en pp. 465 y 447.

54. Marqués de Castejón, 1774, AGS, SSH, leg. 50.

55. Belderrain. Cádiz 11-8-1760, AGS, Marina, leg. 610. 
toda la Armada, «es preciso que VS se valga de su maña, y no solo de inteligentes, para solicitar en este contrato toda la posible conveniencia a la Real Hacienda, respecto de la gruesa cantidad que se anticipa al asentista y la puntual segura paga de lo que se proveyese» ${ }^{56}$. El precio no reflejaba exactamente lo que el suministro valía, sino más bien lo que se había negociado, y en un asiento se negociaba prácticamente todo: el tiempo de duración del contrato, las fianzas del asentista, el modo de pago, los anticipos entregados por la Real Hacienda, cantidades, lugares de entrega, impuestos, privilegios y un largo etcétera. Cambiar cada uno de esos elementos podía alterar el precio final, sin que para nada hubiese intervenido una modificación en las condiciones del mercado, y el Estado aprendió las ventajas de enfrentar a los asentistas en una negociación paralela al procedimiento de subasta pública: «el Rey manda que se diga reservadamente a Aragorri que los Gremios han hecho la baja... por si está en ánimo de hacer otra mejora» ${ }^{57}$.

En estas negociaciones paralelas entre Estado y asentistas había un sorprendente límite: la opinión pública. Durante todo el siglo, pero de forma clara en la segunda mitad del siglo xviII, el Estado procuró seguir en los asientos la máxima de que los precios no aumentasen respecto a los anteriores. La memoria institucional funcionaba como el principal mecanismo regulador del precio, y siempre que se iniciaba una negociación se pedía informes sobre cuáles habían sido los precios anteriores. El objetivo de estas miradas retrospectivas era justificar el mantenimiento, el descenso o, en el peor de los casos, la ligera subida del nuevo precio, porque eran conscientes de que el precio sería finalmente publicado y conocido. Aunque pueda resultar extraño, para el Estado español era muy importante lo que opinase «el público», y se hacían auténticos esfuerzos para que el precio recogiese lo que ellos llamaban «economía», hasta el punto de que hemos encontrado casos de verdadera ocultación del precio público de un suministro, y que se hacía por un presumible temor a la opinión pública. Así se reconocía expresamente en un asiento de víveres para el ejército en 1756 al admitir que, para que el precio final acordado entre la Secretaría de Hacienda y el asentista fuese igual que el anterior se podían compensar los precios entre los diversos suministros que incluía el asiento: «para que a los que no tienen experiencia, no cause disonancia, este último precio se puede aumentar en la ración, y bajar en correspondencia en la cebada» ${ }^{58}$. En algún caso la negociación incluyó la ocultación del precio real acordado entre el Estado y asentistas, incluso con la expresa autorización del propio secretario de Hacienda: «Yo cumpliré a vmds mi palabra de que no se publicaran sus precios» ${ }^{59}$.

56. Marqués de Ensenada a Andrés Marver y Vera, Madrid 12-9-1750, AFB, Judicial, Corregidor/ Civil, 694/23.

57. Miguel Múzquiz, 3-10-1771, AGS, SSH, leg. 645.

58. AGS, SSH, leg. 641.

59. Miguel Múzquiz a Cinco Gremios Mayores, 4-10-1772, AGS, SSH, leg. 645. 
Un factor que aparecía con fuerza en la negociación del precio entre el Estado y asentistas era la forma de pago del suministro. En concreto, el punto más conflicto era si la Real Hacienda adelantaba al asentista el coste total en mensualidades o anualidades, denominados anticipos o «mesadas». El coste se estimaba con los datos de consumo del Estado de cada suministro en los años anteriores. Las mesadas permitían resolver un problema de contabilidad importante. Antes de procederse al pago por los suministros entregados, el Estado debía comprobar los certificados emitidos por los comisarios de guerra y ordenadores, reunidos por las tesorerías de Ejército, elevados a la Tesorería General y finalmente, todo ello, comprobado por el Tribunal Mayor de Cuentas. Este era un largo proceso de control contable en el que se podían emplear varios años y provocar insufribles retrasos a los asentistas. Para los proveedores estas consignaciones eran un medio de hacer efectivo el pago sin acumular insoportables retrasos, al tiempo que un eficaz instrumento de financiación con el que sostener su crédito. Los asentistas que gestionaban la fábrica de cañones de bronce de Sevilla, por ejemplo, necesitaban estas consignaciones, precisamente, para mantener el crédito con el que realizaban las compras de materiales en los mercados internacionales ${ }^{60}$, y sabemos que algunos asentistas llegaron a negociar con esas anticipaciones ${ }^{61}$. Para los asentistas estas «mesadas» se convirtieron en algo esencial, y en algún caso, como los asentistas de construcción de seis navíos por asiento en 1766, lo fijaron por contrato: «Si no se le paga mensualmente, cesará la obra y se le indemnizará por la suspensión ${ }^{62}$. Este método de anticipaciones no se puede calificar como una imposición de los asentistas al Estado español, sino que era el sistema habitual en Europa, donde hasta el Estado británico lo empleaba con sus asentistas y, además, era considerado como «un sistema que animaba el rápido cumplimiento de contratos» ${ }^{63}$. No obstante, el método de las anticipaciones fue un argumento recurrente en los discursos de los administradores para demostrar precisamente lo contrario, el «despilfarro» de la Real Hacienda, y una prueba concluyente contra los excesos de los asentistas. Como afirmaba Fermín Buenaventura «es preciso confesar que si se dieran a la Administración la anticipación y consignación que pide D. Manuel Santos, me parece que no saliera a más precios

60. Aguilar Escobar: Cañones de brone..., p. 93.

61. El Consejo de Hacienda declaró que era motivo de fraude: «En este proceder de los D’Hugues advierte el Consejo dos fraudes, pues habiendo capitulado entregar las mesadas en las arcas de Partearroyo, se las cedieron después a Larralde, y luego solicitó y con efecto recibió la de octubre, dejando a los dos en este descubierto", Madrid, 12-11-1763, AGS, SSH, leg. 642.

62. Las mesadas eran de 25.000 pesos ( 375.000 rsv) a recibir de 1768 a 1772 . Se utilizaba como indicador la cantidad pactada en el anterior asiento de Manuel Zubiría, Arriaga, Madrid 23-10-1766, AGS, Marina, leg. 607.

63. Morris: The Foundations of British Maritime..., pp. 107-108. Varios ejemplos en BAKER, N.: Government and Contractors: the British Treasury and War Supplies, 1775-1783. Londres, 1971, pp. 56-57. 
que los que refiere este supuesto, porque con los tres millones de rsv prontos, se podría asegurar ahora trigo de dentro y fuera del reino con alguna conveniencia» ${ }^{64}$.

Lo que hacía que este método fuese una cuestión central en las negociaciones era que obligaba a la Real Hacienda a enfrentarse con el problema de que necesitaba una mayor liquidez en sus arcas reales. Precisamente fue su crónica falta de liquidez, mantenida durante todo el siglo, la que hizo que las «mesadas» fuesen un elemento clave en el proceso de negociación de los contratos de suministros. Los asentistas reclamaban el pago mensual y lo más ajustado posible al gasto real contratado, mientras que la Real Hacienda pretendía reducir y retrasarlo lo más posible. El margen de maniobra para la Real Hacienda fue cada vez menor, puesto que en la primera mitad del siglo xviI pudo resolver el pago de las «mesadas» mediante su vinculación o consignación a los ingresos de determinadas rentas ${ }^{65}$, pero en la segunda mitad, tras el paso de la recaudación de algunas rentas reales a la administración, el Estado estuvo obligado a intensificar el proceso de negociación de las anticipaciones con los asentistas. La negociación de cada renovación de asiento se convirtió entonces en algo complejo, especialmente en los asientos más importantes. Las pretensiones del Estado de imponer bajas a las anticipaciones solo podían ser aceptadas por los asentistas a cambio de negociar el número de años del contrato o cualquier tipo de privilegio, incluido el monopolio. Se trataba de un juego peligroso, en el que cuanto más importantes fuesen las anticipaciones, más complejas eran las negociaciones, y mayores las contrapartidas. De hecho, hubo administradores conscientes del peligro y preferían excluir las anticipaciones, como admitió la Junta del Departamento Marítimo del Ferrol, quien concluía en una negociación de asiento: «razón porque no convendría anticipar nada a los asentistas, además tienen el inconveniente las anticipaciones que muchas veces precisa a admitirles lo que no es arreglado a contrata» ${ }^{66}$. No obstante, la realidad se imponía y las anticipaciones finalmente casi siempre se incluían en la negociación. Los equilibrios entre todos estos factores eran muy diferentes en cada caso, pero siempre con el referente de que el precio final publicado no fuese «escandaloso», de tal manera que el estancamiento o la bajada en el precio de un asiento

64. Informe de Fermín Buenaventura Folch a Fernando Verde Montenegro sobre la propuesta de provisión de víveres hecha por Manuel Santos, administrador de la casa del Marqués de Valdeolmos, Madrid 22-9-1740, AGS, SSH, leg. 640.

65. La unión entre arrendadores y asentistas durante el reinado de Felipe V no debería entenderse exclusivamente como una imposición política de los hombres de negocios al Estado; a nuestro juicio, cabe también una lectura más pragmática, por la que el Estado lograba la liquidez necesaria para asegurar los suministros militares, sin por ello poner en cuestión la autoridad real, ya que era el Estado quien finalmente decidía qué asentista y qué anticipación. El mejor trabajo disponible sigue siendo IBÁñez Molia, J.: Rentas Provinciales, administración real y recaudadores en el reino de Felipe $V(1700-1739)$. Granada, Tesis doctoral en microfichas, 1985.

66. Consignación Departamento Marítimo del Ferrol, 1777, AGS, SSH, leg. 50. 
era el resultado de toda esa negociación, que podía incluso ocultar un aumento en la cantidades anticipadas por el Estado. El mecanismo podía funcionar en la dirección contraria, y la renuncia a recibir la anticipación podía ser la mejor baza para que el Estado autorizase el cambio de los titulares de un asiento, sin que el precio se modificase ${ }^{67}$.

Por lo tanto, si la administración tenía un grave problema para identificar el coste real de los suministros cuando era proporcionados por el Estado, y el precio en los asientos respondía más a una negociación en la que intervenían muchos más factores, el resultado es que el Estado no trabaja en la dirección de conocer e imponer el método más eficaz, al menos desde el punto de vista económico. Si la economía no era tampoco tan importante, de nuevo se imponía una interpretación pragmática: lo importante era tener el producto, el cuánto costaba era secundario. En medio de una compleja negociación de asiento de víveres entre los Cinco Gremios Mayores y la secretaría de Hacienda en 1772, Miguel Múzquiz lanzó un órdago para que los asentistas redujesen sus pretensiones: «se le amenace con pasar las dos actividades (provisión de víveres y gestión de Excusado) a administración... y si aún metiesen la cabeza a no abrazar el partido, conviene que se ponga en ejecución la administración, por la mano o manos que parezca más a propósito a VS, y que no sea ninguna de los Gremios, para que salga mejor la cuenta al Rey, y los halle VS en adelante con más moderación» ${ }^{68}$. La prioridad para el ministro estaba clara, el resto era todo negociable, incluido el método de suministro, los privilegios concedidos, el precio o las anticipaciones. Y en esa negociación la última palabra la tenía siempre el Rey, porque era él quien daba el exacto valor a lo concedido, por lo que su autoridad se reforzaba en cada nueva renovación.

Esta creciente politización del precio de los suministros tenía que ver, como veremos a continuación, con el margen de maniobra política que en la realidad ofrecía al Estado un contrato de abastecimiento y que, en definitiva, hacía que los límites entre asiento y administración se diluyesen.

\section{La acción Política. Mercantilismo compartido}

En la tesis de Thompson, con el recurso al asiento el Estado perdía parte de su capacidad de desarrollar acción política. Creemos que para el Estado de los Borbones esto no fue tan evidente. Es más, pensamos que, precisamente, una de

67. Torres Sánchez, R.: «In the shade of power. Monopolist entrepreneurs, the State and Spanish Military Victualling in the Eigthteenth Century» en Fynn-PAul, J. (ed.): War, Entrepreneurs, and the State. Brill, Leiden, Netherlands, 2013, pp. 17-45.

68. «Informe reservado», Madrid, 5-11-1771, AGS, SSH, leg. 645. 
las razones de que no se impusiese un sistema de provisión determinado estuvo en que el Estado de los Borbones pudo ejercer la acción política sin mayores cortapisas. El Estado estuvo en condiciones de ejercer plenamente su autoridad, sin ningún límite, independientemente de si la provisión procedía de la administración o de asiento.

Quizás en el terreno donde fue más clara la existencia de una orientación política en el terreno del abastecimiento militar fue en el seguimiento de los principios mercantilistas. Aunque pueda parecer una obviedad repetir el hecho de que la acción política estuvo en buena medida presidida por ideas mercantilistas, lo cierto es que lo fue en una medida incluso más importante de lo que se podría creer. Como viene insistiendo la historiografía, el mercantilismo no fue solo una corriente de pensamiento sino también uno de los principales motores de acción política durante todo el siglo XVIII, incluso de forma destacada en Gran Bretaña. Según Kenneth Morgan, sus «políticas mercantilistas, sostenidas por un Estado fiscal-militar y una exitosa dirección de la guerra, permitieron a Gran Bretaña forjar un imperio global» ${ }^{69}$. Patrick O’Brien llega a afirmar que una mirada histórica atenta de lo que él llama «mitos liberales y realidades mercantilista» permite sostener que el éxito inglés durante el siglo XviI fue fundamentalmente el éxito del Estado europeo más mercantilista, porque fue el que mejor logró asegurar en el reino «seguridad, estabilidad y soberanía», objetivos últimos del Estado y base esencial para sostener el crecimiento ${ }^{70}$. En la España del siglo XVIII también había una destacada unanimidad en perseguir esos objetivos, y las ideas mercantilistas de Uztáriz fueron una guía permanente durante toda la centuria. El principal objetivo de la acción política era la seguridad nacional y el beneficio y estímulo de la economía del reino. La unión de ambos elementos se podía alcanzar con una política que permitiese asegurar el abastecimiento militar de expresa producción nacional, que evitase la necesidad de que la riqueza fuese a parar a manos extranjeras, ya fuese porque los proveedores no fuesen súbditos o porque hubiese que pagar en el exterior por suministros. Cuando, por ejemplo, el secretario de Marina, marqués de Castejón, exponía en 1781 que la mejor y única política de abastecimiento de cáñamo era fomentarlo en España, lo argumentaba porque este suministro se convertía en un medio útil de acción política: «para

69. Morgan, K.: «Mercantilism and the British empire, 1688-1815» en Winch, D. y O'Brien, P. K. (eds.): The Political Economy of British Historical Experience, 1688-1914. Oxford, 2002, pp. 165-191.

70. Esta tesis en O'Brien, P.: «Taxation for British Mercantilism from the Treaty of Utrecht (1713) to the Peace of Paris (1783)», en Torres Sánchez, R.: War, State and Development... pp. 295-356. Una elaboración más detallada de la tesis en O’Brien, P.: «The nature and historical evolution of an exceptional fiscal state and its possible significance for the precocious commercialization and industrialization of the British economy from Cromwell to Nelson», The Economic History Review, 64:2 (2011), pp. 408-446. 
sostener nuestra Marina, la del Comercio Nacional y evitar que en los sucesivo se extraigan tantos millones fuera del Reino» ${ }^{71}$. Es decir, sus argumentos se limitaban a repetir las ideas mercantilistas de Uztáriz. Para la mayoría de los gestores públicos españoles era una verdad indiscutible que a través de la reserva del consumo de las fuerzas armadas españolas a la producción nacional se lograrían beneficios económicos y políticos, y el modelo para ellos era Gran Bretaña. Todavía en 1792 para el secretario de Hacienda Diego Gardoqui el modelo de política económica a seguir era «el modelo inglés», que en palabras del ministro se resumía en un uso inteligente de la protección del consumo nacional: «tres especies de medios además de las prohibiciones han seguido y siguen los Ingleses, que son ciertamente los que con más celo, vigilancia y fruto han cuidado del fomento de su riqueza nacional» ${ }^{72}$. Como sostiene Guillaume Garner, la presencia y la influencia de las ideas mercantilistas en el discurso político del siglo xviII se explican por la necesidad del Estado de hacer efectiva su autoridad y soberanía, lo que él llama «economía territorial» ${ }^{73}$.

La vigencia de estas ideas entre los gestores españoles durante todo el siglo queda reflejada en las recomendaciones que hizo el secretario de Marina y de Hacienda Salazar sobre la mejor política de suministros, quien reclamaba un claro programa mercantilista: «como lo aseguran con sobrada razón el Sr. Ustariz y todos los economistas...» ora políticas, ora económicas, el que los surtimientos de todas clases sean siempre y en cuanto fuese dable de géneros nacionales, aun dado caso que su calidad sea inferior y precio mucho más subido que el de los extranjeros; porque como la riqueza del Estado es una misma que la de los individuos que lo componen, los caudales que de las arcas del erario pasan a manos de los particulares, siendo propiedad de españoles, no empobrecen a aquel de ninguna manera, sino que por mil rodeos vuelven a engrosar sus fondos; y este perpetuo círculo es el que da vida a los gobiernos al modo que el de la sangre la da a los animales» ${ }^{74}$. De nuevo lo prioritario no es el precio de los suministros, y para Salazar lo importante es su posibilidad de acción política.

Estas ideas mercantilistas expuestas en 1814 nos indican que no estamos hablando de ideas teóricas o aplicables solo a las etapas iniciales del siglo xviII, sino que marcaron profundamente la política del Estado hacia los suministros militares durante todo el siglo. Ahora bien, la cuestión para nosotros es si ese «programa» mercantilista se podía desarrollar solo mediante la administración,

71. Castejón a Múzquiz, 2-10-1781, AGS, SSH, leg. 51.

72. Diego Gardoqui, 1792, AHN, Estado, leg. 232.

73. GaRnER, G.: «Caméralisme et territoire. Ėtat, espace et économie dans le discours économique allemand au XviIIe siècle», Revue $d u$ Nord, 85 (octubre-décembre 2003), pp. 729-745, referencia en pp. $730-731$.

74. Salazar, Juicio crítico de la marina militar.., Carta III, Enero 1814, p. 78 y Carta XXIV, Mayo 1814, p. 122. 
lo que habría justificado la elección de este sistema como instrumento de acción política. Lo que nos muestra la relación entre el Estado y los asentistas es que esas ideas mercantilistas fueron ampliamente compartidas también por los asentistas, que hicieron suyo el discurso oficial imperante, y que los asientos sirvieron igualmente al Estado de los Borbones para poner en práctica su política marcadamente mercantilista. Cuando el asentista privado de vestuario Marcos Antonio de Andueza propuso en 1780 un nuevo contrato de vestuario para las tropas de América, Andalucía y Ceuta de 12 años lo justificó con argumentos mercantilistas, plenamente identificados con los deseos del Estado: «con el fin de fomentar las fábricas y manufacturas, extendiendo el beneficio que con este ramo había logrado solo el Principado de Cataluña hasta aquí en (a) las demás Provincias del Reino,... desterrando la mayor parte de la mendicidad... Que siendo el ánimo de VM promover, y fomentar cuanto sea posible las fábricas en aquellos cuatro reinos de Andalucía, me obligo a que la construcción de dichos vestuarios sean hechos con géneros de paños y estameñas de las fábricas de aquellas provincias de Andalucía... ${ }^{75}$. Del mismo modo, los discursos de los directores del Banco de San Carlos al justificar el interés de su gestión al frente del asiento de víveres son igualmente mercantilistas, priorizando un abastecimiento nacional: «prefiriéndose, no obstante, en cuanto sea compatible con la utilidad de este las producciones de estos Reinos, conforme está prevenido en la Real Cédula de Erección del Banco para el fomento de la agricultura e industria de ellos» ${ }^{76}$. Los ejemplos son muchos, pero la conclusión es la misma: el Estado podía desarrollar una política mercantilista también con el recurso a los asientos, porque los asentistas, por conveniencia o por convicción, compartían plenamente el discurso político dominante. Esta sincronía reducía también la trascendencia política de elegir entre administración $\mathrm{o}$ asiento, y con ello la vigencia de ambos sistemas.

Ahora bien, que se pudieran aplicar ambos modos de suministro para conseguir los mismos objetivos mercantilistas no asegura que estos se alcanzasen, ni siquiera que uno u otro modo asegurase un mayor nivel de éxito en el ideal mercantilista. En los resultados prácticos de la política mercantilista encontramos que hay una diferencia notable si hablamos de asentistas o de suministros. En cuanto a los hombres de negocios, el éxito fue completo, y con él un triunfo de los principios mercantilistas del Estado borbónico. Es decir, a lo largo del siglo xviII se consiguió y se mantuvo un completo dominio de los proveedores españoles sobre los suministros militares. El proceso de sustitución de nacionalidad en los asentistas es todavía mal conocido. No obstante, contamos con estudios que insisten en que la fuerte entrada de extranjeros en esta actividad desde finales del siglo xvI,

75. Madrid, 6-1-1779. AHN, FCH, leg. 6732.

76. San Lorenzo, 10-xi-1783. AGS, DGT, inv. 25, leg. 15. 
como ya destacara Thompson, fue compatible con la continuidad de proveedores españoles durante el siglo XVII y con un proceso de sustitución y expansión anterior a 1700. La intensa actividad bélica en la Península y la movilización local de recursos militares facilitó el desarrollo de los asentistas españoles, algunos de los cuales llegaron a constituir casas de negocios de gran capacidad, hasta el punto de poder actuar en otros territorios de la monarquía ${ }^{77}$. Esta dinámica de expansión de los asentistas españoles no se detuvo con el cambio de dinastía y la llegada de políticos, asentistas y suministros franceses. Ni la capacidad de influencia política de Orry, con pasado y conexiones con asentistas franceses ${ }^{78}$, ni la necesidad de importaciones masivas de suministros de Francia durante la Guerra de Sucesión ${ }^{79}$ lograron crear las condiciones efectivas para permitir el avance de los proveedores franceses. Como sostiene Jean Pierre Dedieu fue la necesidad financiera de Felipe V la que finalmente decantó el favor real hacia los españoles, y con él la supervivencia de los asentistas españoles, en un enfrentamiento que el profesor francés identifica entre «el grupo» de Jean Baptiste Orry y el «conglomerado» Goyeneche ${ }^{80}$. Esta lucha probablemente se debería comprender en un contexto más amplio de soterrada pero muy intensa lucha de varios países europeos por el mercado español, en la que, como ha demostrado Pérez Sarrión, no hubo ninguna involución y salieron triunfantes los intereses españoles. El resultado de todo este proceso era muy visible ya tras la Guerra de Sucesión, cuando todos los asientos militares estaban controlados en todos sus niveles, desde titulares a factores, pasando por fiadores, por españoles. No conocemos todavía bien las claves de este triunfo de los hombres de negocios españoles pero debió desempeñar un papel esencial el

77. El problema está planteado en Rodríguez Hernández, A. J.: Los tambores de Marte: el reclutamiento en Castilla durante la segunda mitad del siglo XVII (1648-1700). Valladolid, 2011. Véase también SANZ Ayán, C.: «Negociadores y capitales holandeses en los sistemas de abastecimientos de pertrechos navales de la monarquía hispánica durante el siglo XVII», Hispania, 182 (1992), pp. 915-945. Esteban Estríngana, A.: «Administración militar y negocio de guerra en los Países Bajos católicos. Siglo XviI» en Crespo A. y Herrero, M. (eds.): España y las 17 Provincias de los Países Bajos. Una revisión historiográfica (XVI-XVIII). Córdoba, 2002, tomo I, pp. 65-100. JimÉNEZ EsTrella, A. y F. AndúJar Castillo (eds.): Los nervios de la guerra. Estudios sociales sobre el ejército de la Monarquia Hispánica (ss. XVI-XVIII): nuevas perspectivas. Granada, Ed. Comares, 2007.

78. Dubet, A.: Un estadista francés en la España de los Borbones. Juan Orry y las primeras reformas de Felipe V(1701-1706). Madrid, 2008, p. 54.

79. Calvo Poyato, J.: «La industria militar española durante la Guerra de Sucesión» Revista de Historia Militar, 33:66 (1989), pp. 51-71.

80. Dedieu, J. P.: «Les intermédiaires privés dans les finances royales espagnoles sous Philippe $\mathrm{V}$ et Ferdinand VI» en V. MeyzIE (ed.): Crédit public, crédit privé et institutions intermédiaires. Monarchie française, monarchie hispanique, XVIe-XVIIIe siècles. Limoges, 2012, pp. 223-239. Véase nota 9. Al grupo francés de Orry, añade también a Sartine Dedieu, J. P.: «Les groupes financiers et industriels au service du roi. Espagne, fin XVIIe-début XVIIIe siècle» en DubET, A. y Luis J. P. (eds.): Les financiers et la construction de l'Etat - France, Espagne (XVIIe-XIXe siècle). Rennes, 2011, pp. 87-104 y 103. 
apoyo decidido de la autoridad real, sin duda por la propia debilidad financiera del Estado, la necesidad de contar con capitalistas solventes y con la entrada de algunos de ellos en la misma maquinaria del Estado. De cualquier modo, el dominio absoluto de los españoles en los suministros militares fue indiscutible entonces y en el resto del siglo, sin duda un auténtico éxito mercantilista.

La continuidad del dominio español no se puede explicar exclusivamente por una cuestión de inercia; también hubo que pelear para sostenerlo, y en esa lucha colaboraron los asentistas españoles. En algún caso se puede comprobar perfectamente que fueron los propios asentistas españoles los que contribuyeron de forma activa a mantener el dominio nacional y a enfrentarse y excluir a los extranjeros. Cuando en 1763 toda la provisión de víveres al ejército español fue concedida por el marqués de Esquilache a dos asentistas franceses, hermanos Dughes, acción esta interpretada por Michel Zylberberg como un ejemplo claro del «triunfo» de los franceses en el control de la economía española ${ }^{81}$, en realidad lo que se produjo fue una auténtica guerra animada por asentistas españoles y que provocó la caída de estos asentistas franceses en menos de un año. Un análisis detallado de este conflicto de intereses muestra con claridad la posición de fuerza que detentaban los españoles y la voluntad expresa de no permitir la entrada de unos extranjeros en el asiento. De nada sirvieron los apoyos explícitos de la embajada francesa ni la posición vacilante de Esquilache para frenar los ataques españoles, los asentistas españoles tenían suficiente capital, de hecho prestaron dinero a los propios Dughes, y contaban con la red de corresponsales y factores sin la cual era imposible operar. Tras una serie de acciones bien orquestadas y dirigidas a desacreditar a los asentistas franceses, los Dughes acabaron refugiándose en la embajada francesa. Las últimas quejas de los Dughes a Esquilache ilustran el tono de todo lo que había ocurrido: «todo esto Excmo. Sr. nos acredita el poco afecto que merecemos a la nación». Estas palabras fueron ratificadas por la vía diplomática, con la protesta expresa del embajador francés en la misma dirección: «ha sido este un acontecimiento tan ruidoso, que fomenta aún en los menos advertidos una especie de descrédito público contra todos los franceses establecidos en España» ${ }^{82}$. En este caso no fue el Estado sino los propios asentistas españoles los que defendieron la «economía territorial», y con ello lograron fortalecer los principios mercantilistas del Estado.

En la misma dirección debería interpretarse, a nuestro juicio, el éxito de otro francés y su entrada en las provisiones, como fue Francisco Cabarrús, que logró

81. Zylberberg, M.: Une si douce domination. Les milieux d'affaires français et l'Espagne vers 1780-1808. París, 1993, p. 167.

82. Marqués de Ossun a marqués de Esquilache, 13-12-1763, AGS, SSH, leg. 642. El caso es analizado en Torres SÁnchez, R.: «Las dificultades de ser financiero extranjero en la España de Carlos III», I Coloquio Internacional «Los extranjeros en la España Moderna». Málaga, 2003, tomo II, pp. 771-780. 
hacerse con la mayor parte de ellas al incluirlas entre las actividades del Banco de San Carlos, de nuevo interpretado como otro triunfo francés ${ }^{83}$. Cabarrús no estaba interesado en el abastecimiento militar. Su principal objetivo era el monopolio de la exportación de plata, que el Estado aceptó conceder por la solución ofrecida de Vales Reales al problema de deuda pública, pero la entrada en el negocio de los suministros le llevó a un enfrentamiento con los anteriores asentistas, que con los Cinco Gremios Mayores al frente, el apoyo del tesorero general Francisco Montes y el beneplácito del secretario de Hacienda, Pedro Lerena, lograron en pocos años desacreditarlo y expulsarlo de todos sus negocios ${ }^{84}$. Una vez fuera, y con el marqués de Hormazas (antiguo asentista de víveres de la Armada) ${ }^{85}$ en la dirección del Banco, todos los asientos volvieron a ser concedidos a asentistas españoles. El triunfo de Cabarrús en los suministros militares apenas duró 5 años y la causa de su fracaso fue la oposición de los españoles. A nuestro juicio, la rápida y fulgurante caída de Cabarrús nos habla, no tanto de la influencia francesa, como de la capacidad alcanzada por los hombres de negocios españoles para defenderse de la entrada extranjera. Sin duda, un nuevo triunfo mercantilista.

El Estado borbónico, con la participación de los asentistas españoles, logró que los suministros militares se mantuviesen en manos españolas, pero no obtuvo el mismo éxito a la hora de limitar el origen de los abastecimientos a la producción nacional o imperial. En realidad, el ideal mercantilista del autoabastecimiento no pudo lograrse ${ }^{86}$. Prácticamente en todos los suministros hubo que recurrir a la importación exterior para completar la producción nacional: pólvora, cañones, buques, brea, clavos, herrajes, cáñamo, víveres... y hasta soldados. De los 82 batallones de infantería existentes a mediados del siglo XVIII, el $21 \%$ estaba compuesto por extranjeros ${ }^{87}$, y la necesidad de acudir a mercenarios extranjeros siguió aumentando durante el resto del siglo ${ }^{88}$. La incapacidad de cumplir con el ideal mercantilista de autoabastecimiento, no obstante, no debería, a nuestro

83. Zylberberg, M.: «Des affaires à l'administration: un échec de François Cabarrus» en VINCENT, B. y Dedieu, J. P.: L'Espagne, l'Etat, les Lumières: mélanges en l'honneur de Didier Ozanam, 2004, pp. $109-119$.

84. Torres SÁnchez, «In the shade of power...», p. 37.

85. TORRES SÁNCHEz, R.: «Los navarros en la provisión de víveres a la armada española durante el siglo XVIII», en «Volver a la «hora navarra». La contribución Navarra a la construcción de la monarquía española en el siglo XVIII. Pamplona, 2009, pp. 213-264.

86. Díaz Ordóñez, M.: «El riesgo de contratar con el enemigo. Suministros ingleses para la Armada Real española en el siglo XVIII", Revista de historia naval, 21:80 (2003), pp. 65-74.

87. Según Gabriel Arrieta, el total de soldados en regimientos de infantería era de 59.712, de los que 12.672 pertenecían a regimientos extranjeros, Arrieta, G.: Alphabeto y cartilla militar, Cádiz, 1757, p. 447.

88. Si a mediados de siglo había 9 regimientos de infantería extranjera, en 1781 había ascendido a 12, con un total teórico de 24.768 hombres. TERrón PONCE J. L.: Ejército y política en la España de Carlos III. Madrid, 1997, p. 86. 
juicio, ser exagerado. En realidad ese ideal no fue conseguido por ningún país europeo, ni siquiera en Gran Bretaña, donde pese a su extraordinaria capacidad productiva solo se pudo mantener su ritmo de expansión naval mediante el recurso a la importación masiva de suministros militares ${ }^{89}$. El recurso a los mercados exteriores de materias primas, productos elaborados o técnicos en el siglo XVIII fue bastante fluido, en buena medida porque precisamente era en el área europea donde se concentraron más estados interesados en gastar todos sus recursos en la guerra, y todo ello dio lugar a unos todavía poco investigados mercados europeos de suministros militares ${ }^{90}$.

La cuestión realmente importante para nosotros es si el Estado de los Borbones logró con su política de abastecimiento militar aumentar o reducir esa irremediable necesidad de acudir a los mercados exteriores, que era en definitiva el verdadero objetivo de un planteamiento mercantilista. Nuestra tesis es que en la política de constante variación entre administración y asiento el Estado aumentó su autoridad pero también redujo las alternativas de producción nacional, y con ello se alejó de sus principios mercantilistas. Para comprender esta aparente paradoja, más autoridad y menos mercantilismo, es necesario tener en cuenta otro elemento esencial como fue el principio de exclusividad con el que se desarrolló la política de los Borbones de suministros militares.

\section{LAS «COSEChas PROPIAS». Privilegio y AUtORIDAD REAL}

A nuestro juicio hubo una idea de fuerza poco considerada pero muy presente en las acciones políticas del Estado de los Borbones que fue la exclusividad. El Estado desarrolló una política de suministros que estimuló el que todos los agentes implicados, públicos y privados, compartiesen el deseo de reclamar exclusividad, privilegio y, llegado el caso, monopolio. Para el Estado era una forma de asegurar y garantizar un suministro determinado, y para los particulares era un medio de promoción porque les acercaba a la fuente de poder y autoridad de aquella sociedad. Frente a la interpretación de Thompson, que insiste en la imposición de alguna de las partes, ya sea el Estado a los asentistas o los asentistas sobre el Estado, la realidad que nos aparece con fuerza en el siglo xviII es la de una búsqueda constante de ambos, o si se prefiere, de una interesada colaboración entre Estado y asentistas, que, en definitiva, contribuyó a difuminar aún más los límites entre administración y asiento.

89. Morris: The Foundations of British Maritime..., p. 171.

90. Conway, S.: Britain, Ireland, E Continental Europe in the Eighteenth century. Similarities, Connections, Identities. Oxford, 2011. En la misma dirección, pero para el caso concreto de la marina, véase RODGER, N. A. M.: «From the 'military revolution' to the 'fiscal-naval state'», Journal for Maritime Research, 13:2 (2011), pp. 119-128. 
No podemos establecer quién estaba más interesado en imponer una exclusividad, si el Estado o los asentistas, pero sí que era una beneficiosa forma de proceder para ambos. Como ha demostrado de forma ejemplar Rafael Guerrero, la competencia entre los ferrones guipuzcoanos y vizcaínos no se determinaba en términos de producción o de mercado, sino más bien por el grado de proximidad al rey, ya fuese mediante un contrato de asiento o un encargo de administrador en una Real Fábrica. Conseguir un asiento o un nombramiento real podía alterar profundamente la capacidad de producción del beneficiado, pero con ello también la del resto de productores y por este cambio llegar a modificar las relaciones sociales y políticas de una zona. Así, la descripción que hizo un amigo al asentista de armas Pedro Bernardo de Villarreal no deja lugar a dudas de las repercusiones en la ría de la noticia de su reciente asiento y, sobre todo, advertía que lo que estaba en juego no era solo un negocio económico: «has de saber que con tu asiento y oficinas en Bengolea se han revuelto cuantos duques, condes, armados y no armados de toda esta tierra» ${ }^{91}$. Ser «hombre del rey» ofrecía una herramienta esencial para alterar y reconstruir las relaciones y alianzas de poder y autoridad de una determinada área, al tiempo que permitía elevar la posición del beneficiado hasta poder entrar en contacto con otros grupos y élites nacionales. Si el rey era la única fuente de autoridad, un asiento o un nombramiento real ofrecía un medio valioso de promoción y diferenciación social. Esta dinámica de proyección social al amparo de la autoridad real funcionaba de abajo hacia arriba, es decir, del individuo hacia la oligarquía y élite local y, en el último nivel, hacia las élites y grupos nacionales. Con ello se consiguieron varias cosas. En primer lugar, que las élites locales estuviesen interesadas en participar en la necesidad del Estado de conseguir suministros y que esta no fuese una imposición del Estado, ni mucho menos una cesión de poder; más bien fue lo contrario. Fueron los propios asentistas y élites locales los que buscaron participar y satisfacer la necesidad del Estado, y todo ello contribuyó a reforzar a la fuente de la que emanaba el poder, es decir, la autoridad real. En segundo lugar, ofrecía un factor de renovación de las élites muy potente, porque podía desplazar, como ocurrió en ese ejemplo, a las viejas élites por otras más próximas y leales al servicio al rey, lo que en el reinado de Felipe $V$ fue algo esencial. Por una u otra vía la autoridad del rey se fortalecía.

El coste para el Estado de esa exclusividad era aparentemente barato, puesto que se trataba de otorgar un calculado número de privilegios. Los privilegios concedidos a Reales Fábricas y compañías comerciales eran la punta del iceberg de una actividad mucho más intensa de privilegios a los asentistas, todavía mal

91. Guerrero Elecalde, R.: Las elites vascas y navarras en el gobierno de la Monarquía Borbónica. Redes sociales, carreras y hegemonia en el siglo XVIII (1700-1746). Bilbao, 2012, p. 157. 
conocida, pero que sin duda afectó a muchos más individuos y grupos ${ }^{92}$. Lo importante ahora es destacar que esos privilegios podían ser esenciales para la gestión del negocio y con ello se aseguraba dos cosas, el interés del asentista y la posición de fuerza del Estado y de la autoridad real. De entrada, el asiento implicaba una serie de privilegios que tenían un valor económico y unas posibilidades de negocio que trascendían el mero contrato de suministro. Uno de los más importantes es todo lo que supusiera una relajación de los controles en el tráfico de mercancías y dinero. Así, la concesión de permiso para extraer plata fuera de España, con la excusa de ser necesario para hacer determinadas compras, podía llegar a ser más importante que el propio asiento. $\mathrm{O}$, del mismo modo, el permiso para requisar, con el apoyo de las autoridades locales, medios de transporte como carretas, bueyes o embarcaciones podía marcar la diferencia. La Junta del Banco de San Carlos, por ejemplo, obtuvo para su asiento de provisión de víveres de la Armada el privilegio de poder exigir a «los Ministros de Marina le proveerán de marineros ${ }^{93}$. Como reconocía el asentista marqués de Valdeolmos, si no se disponía de algún instrumento del Estado que avalase su autoridad para embargar carros o comprar con precio de tasa, este negocio debería regularse por las reglas del mercado, y eso no era conveniente en la mentalidad de este asentista: «un Asentista carece de las facultades que sirven para obligar, cuando voluntariamente los vendedores de granos no se convienen, ni los arrieros, ni patrones de barcos, que pretenden precios exorbitantes, y no queda otro recurso, para evitar el daño, que el de pagar a cada uno su deseo» ${ }^{94}$.

La posición de ventaja que adquiría cualquier asentista privilegiado respecto al resto de productores y vendedores hacía que el número y calidad de privilegios obtenidos fuese lo que realmente marcaba la diferencia. Aquí, de nuevo, el Estado diferenciaba según el riesgo que podía existir de desabastecimiento. Así, mientras que autorizaba el privilegio de embargo de transportes a los Cinco Gremios Mayores para el transporte de víveres, negaba el permiso de embargo de carretas a un pequeño asentista que transportaba betunes hasta el puerto de Almería: «no se conceda al asentista la preferencia que pide para el acopio de carretas, pues esto debe ser negocio suyo, sin perjuicio de los particulares, ni la gracia que solicita de privilegios de cabaña Real» ${ }^{95}$. Entre los privilegios que entraban en la negociación había

92. Véanse las reflexiones al respecto de GonzÁlez ENCiso, A.: «La promoción industrial en la España Moderna: intervención pública e iniciativa privada», en Riвот, L. A. y RosA, L. de (eds.): Industria y Época Moderna. Madrid, 2000, pp. 15-46, GonzÁlez EncISo, A.: «El «Estado económico» en la España del siglo XVIII», Memoria y civilización: anuario de historia de la Universidad de Navarra, 6 (2003), pp. 97-139.

93. San Lorenzo, 28-x-1783. AGS, DGT, inv. 25, leg. 15.

94. Inocencio García, administrador general de la casa de negocio del marqués de Valdeolmos, 18-2-1741, AGS, SSH, leg. 640.

95. Gerbaut, Cádiz 18-2-1760. Solicitud de Antonio Soria, vecino de Castril. AGS, Marina, leg. 609. 
uno con un extraordinario valor: el número de cartas o patentes en blanco para que el asentista nombrase empleados y factores de la provisión. El sistema reproducía fielmente el esquema seguido en el reclutamiento privado de soldados, donde también se negociaba la cantidad de nombramientos, en este caso empleos que luego se podían vender $^{96}$. En los suministros militares las cartas en blanco negociadas ofrecían ventajas valiosas a sus poseedores como eran el fuero militar, exención de sorteo de milicias, portar armas, dispensa en el pago de algunos impuestos y una mejora evidente en la condición social local. Sin duda, atractivos estos más que suficientes para que el asentista pudiera atraer a empleados y sostener su red de factores, colaboradores sin los cuales era inviable el asiento. En estas condiciones eran los propios asentistas los primeros en solicitar y sostener la exclusividad como medio de acción política.

El Estado, por su parte, estaba deseoso de atender esa demanda de exclusividad de los particulares porque con ello pensaba que se garantizaba el abastecimiento. Para entender esta lógica de funcionamiento (un productor exclusivo garantiza mejor el suministro militar) es necesario tener presente que esto era precisamente lo que el propio Estado pretendía: el control absoluto de la producción de suministros militares. Si el control se conseguía con un único interlocutor privado o con un administrador público era secundario; lo importante era garantizar el abastecimiento y control del suministro. La alternativa a esta forma de proceder hubiera sido confiar en la libre concurrencia del mercado, aunque fuera exclusivamente nacional, pero esta alternativa implicaba aparentemente tal cantidad de incertidumbre y riesgos que el Estado de los Borbones no estuvo nunca dispuesto a asumirla. A nuestro juicio, el verdadero problema para el Estado no estaba en decidir entre público o privado, sino en el grado de control, y habría que añadir autoridad, que el Estado conseguía y ejercía en el abastecimiento de los suministros militares. En esta lógica la libre concurrencia de las fuerzas del mercado era algo incontrolable, y por lo tanto desechable. Un asentista que reclamaba privilegios y una autoridad que los concedía y asignaba un valor preciso a cada privilegio era un medio de acción política tan útil para lograr el objetivo principal de control de los abastecimientos como podía ser una administración directa. La demanda y concesión de exclusividad, de privilegios, se convertía en la verdadera esencia del sistema y la política de abastecimientos militares de los Borbones.

El principio de exclusividad puso en marcha una dinámica de creciente identificación de objetivos y de medios de actuación entre Estado y asentista, y finalmente de interdependencia. La experiencia había mostrado al Estado los peligros de arriesgar la seguridad del abastecimiento de un suministro a la incierta concurrencia de los asentistas, que no acudiesen en número suficiente a las subastas o que lo hiciesen sin suficiente seguridades y solvencia económica, o, lo que aún

96. Véase el artículo de Francisco Andújar en esta misma revista. 
era más grave, al incumplimiento de un contrato. El instrumento para reducir estos riesgos era precisamente aumentar la exclusividad, y con ello los privilegios. De hecho, un aspecto poco valorado en la política de los Borbones es precisamente la tendencia creciente a lo largo del siglo a confiar en los privilegios como medio de acción política. En su relación con los asentistas, esto se tradujo en contratistas cada vez más privilegiados y apoyados por el Estado, unos asentistas que, por el principio de exclusividad, también fueron reduciéndose en número. Esta dinámica explicaría un hecho evidente y aparentemente contradictorio como es que el momento de mayor intervención del Estado y administración directa, el reinado de Carlos III, coincida con la mayor concentración de asientos en manos de unos pocos asentistas. El éxito de los Cinco Gremios Mayores fue posible gracias a esta dinámica, que fue continuado brevemente en manos de otro asentista, el Banco de San Carlos, quien contrató con el Estado utilizando frases tan claras de qué estaba en juego como: «... con preferencia de cualquiera otro privilegiado»" Precisamente estos asentistas protagonizaron con la máxima intensidad en el siglo el último estadio de esa dinámica de creciente exclusividad, que fue el monopolio de facto. La tendencia estuvo presente durante todo el siglo, ya Orry habló de la conveniencia de poner bajo un asentista el suministro de todo el ejército ${ }^{98}$, pero la dinámica se aceleró desde mediados del siglo, a medida que el Estado ya no podía compensar los servicios de los asentistas con el arrendamiento de rentas y cuando el Estado quería aumentar las garantías de abastecimiento. El resultado fue una creciente interdependencia entre Estado y asentistas y la necesidad de que el Estado apoyase y sostuviese directamente a los asentistas. Como recordaba en 1767 el marqués de Esquilache al intendente de Extremadura ante la posible quiebra de los factores en aquella provincia de unos asentistas, «que es forzoso tratarlos con equidad, porque ni estos, ni otros pueden cumplir los repuestos capitulados»"9 . Unos asentistas que operaban bajo la autoridad del Estado, que reclamaban y obtenían privilegios para gestionar sus negocios, porque con ello el Estado garantizaba mejor el suministro, que se identificaban con los objetivos mercantilistas del Estado y que, en caso de fracaso, podían ser sostenidos directamente por el Estado, ya que era el Estado el primer interesado en que el abastecimiento continuase, eran una mera prolongación del Estado. A nuestro juicio, la realidad muestra que el límite entre administración o asiento era muy tenue, cuando no casi inexistente, como también lo demuestran los constantes cambios de modelo de gestión y la utilización de forma indistinta de los hombres de negocios, como asentistas o como administradores.

97. Se repite en numerosos contratos militares. Varios de ellos en AGS, DGT, inv. 25, leg. 14.

98. DubET, A.: Un estadista francés..., p. 191.

99. Marqués de Esquilache a Sebastián Gómez de la Torre, agosto 1767, AGS, SSH, leg. 644. 
Este principio de exclusividad era igualmente aplicable cuando era el Estado el que gestionaba directamente un abastecimiento. Que un suministro fuese producido por el Estado no tenía por qué implicar la anulación de otras fuentes de abastecimiento nacional, ya que podían ser perfectamente compatibles, incluso ventajosos, como demuestra el caso inglés. Pero la realidad que aparece en los estudios y documentación es que el Estado borbónico, cuando pudo, intentó imponer una exclusividad en su producción. Los argumentos tradicionalmente ofrecidos por los historiadores de que este se justificaba por el deseo del Estado de impulsar el avance tecnológico y conseguir unificar y controlar la calidad son al menos discutibles. En algunos productos suministrados a las fuerzas armadas el componente tecnológico era importante. Un control más directo del Estado podía mejorar la implantación de una nueva tecnología porque se controlaba directamente el modo de producción y se eliminaban más directamente los obstáculos que pudieran surgir en su aplicación. Esta labor de renovación tecnológica del Estado ha fascinado tradicionalmente a los historiadores, quienes la han interpretado de forma mayoritaria como una decidida apuesta por la modernización ${ }^{100}$. El problema es que no siempre se han podido valorar ni contrastar los verdaderos costes de su introducción, ya sea por la necesidad de crear una infraestructura (edificios, técnicos, herramientas) o por la destrucción de las empresas y actividades existentes, ni tampoco se han valorado los efectos para el objetivo principal: contar con mejores suministros para el Estado. Creemos que se ha prestado más atención a la novedad tecnológica que a los efectos reales producidos.

Los ejemplos son abundantes, especialmente en el sector de la siderurgia. En el caso de la producción de cañones de bronce el Estado decidió después de la Guerra de los Siete Años introducir una nueva forma de producir los cañones, fundidos en sólido y luego taladrados, en lugar de fundidos por moldes. Esta decisión se tomó pese a que unas pruebas realizadas con esta nueva técnica en Sevilla en 1757 fracasaron y pese a la mayor necesidad de cobre que requería, cuando en España había un problema de acceso al mercado de metales. La aplicación de la técnica exigió traer a técnicos, pagarles elevados sueldos y honores desproporcionados, construir un nueva fábrica, cuyo coste superó los 6 millones de reales (la asignación mensual de la Real Hacienda a la fábrica fue hasta la década de los 1760 de 720.000 rsv $^{101}$ ), y paralizar la producción, que entre 1767 y 1774 alcanzó unos mínimos de solo 84 piezas frente a las más de 300 conseguidas en la década

100. Cabello Vázquez, R.: «Ciencia y guerra en los albores de la química como disciplina: programa francés para la producción de pólvora», en AstigarRaga, J. et. al.: Ilustración, ilustraciones. San Sebastián, 2009, vol. 2, pp. 715-734.

101. La consignación anual que pagaba la Real Hacienda fue aumentada entre 1775 y 1808 en un $35 \%$, llegando a los 1.125 .000 rsv. El gasto total de la Tesorería General en artillería era de 5.8 millones, lo que supone algo menos del 20\%, Aguilar Escobar: Cañones de bronce..., p. 269. 
de 1750. Todo ello para finalmente obtener unos pobres resultados técnicos ${ }^{102}$, con un precio desproporcionado, tal y como informaba el embajador inglés a su gobierno cuando asistió a las pruebas, para quien estos cañones habían resultado «demasiado costosos para ser de algún servicio más allá de adornar la entrada de un arsenal» ${ }^{103}$. Aún más grave fueron las consecuencias de la renovación tecnológica en la producción de cañones de hierro en Liérganes y La Cavada, que provocó un caos administrativo, el hundimiento de la producción y la necesidad de realizar la mayor importación de cañones del siglo: 4.498 comprados en Gran Bretaña ${ }^{104}$. Todo ello resulta sorprendente cuando el Estado no parece que tuviera ningún problema en imponer a los asentistas productores de cañones los nuevos reglamentos oficiales de calibres de artillería, sin que estuviesen directamente bajo la administración ${ }^{105}$. Del mismo modo, la introducción y aplicación del nuevo sistema de construcción naval a la inglesa de mediados de siglo motivó graves problemas y retrasos en los arsenales peninsulares y solo pudo finalmente desarrollarse cuando el Estado retornó a los asentistas cantábricos y habaneros y la impuso en los asientos ${ }^{106}$. Es decir, la tecnología, como la autoridad, no podía ser aplicada exclusivamente tras las tapias de un arsenal del rey.

No creemos que el Estado tuviese un verdadero problema para imponer una calidad determinada en los suministros que necesitara. En realidad el problema de la calidad no era tal, bastaba con que las condiciones en los asientos estuviesen claras y que el encargado de recibirlas certificase que eran conforme a lo contratado por el Estado. Como se acordó en una contrata de vestuario, el asentista se comprometía a «que pondré donde se me mande un vestido completo con todas sus prendas para que se reconozca, y que ha de servir de muestra, existiendo siempre en depósito sellado, para que los demás que se construyesen se reciban con presencia de él»107. Al Estado le bastaba un reglamento y una muestra para unificar las calidades de todos los suministros, tal y como ocurría en el caso inglés, quienes al medio de comprobar lo contratado añadían el de excluir de futuros asientos a los que entregasen productos de menor calidad a la pactada ${ }^{108}$. El problema de la calidad no debía existir, pero en la dinámica de identificación e

102. «El nuevo método tampoco fue completamente satisfactorio pues las piezas resultaban, en algunos casos, algo más frágiles que las fundidas con las técnicas antiguas» Aguilar Escobar: Cañones de bronce..., p. 199.

103. Lord Grantham Madrid 16-6-1774, PRO, SP-94, fol. 195.

104. Torres SÁnchez, R.: «Velas sin Cañones...», p. 1727.

105. Aguilar Escobar: Cañones de bronce..., p. 117, García-Torralba Pérez, E.: La Artillería Naval Española en el Siglo XVIII. Su evolución técnica y su recíproca influencia con la arquitectura del buque. Madrid, 2010, p. 67 y ss.

106. Valdez-Bubnov: Poder naval..., p. 298.

107. 1780, AHN, FCH, leg. 6732.

108. MORRIs: The Foundations of British Maritime..., p. 130. 
interdependencia entre Estado y asentistas el Estado estaba con frecuencia dispuesto a aceptar menores calidades de las contratadas. Además, había un notable interés de los administradores en utilizar la calidad como argumento para justificar la conveniencia de permanecer al frente de una gestión directa. Así, en un debate planteado sobre si se debía volver al sistema de asiento por la insuficiencia de la producción de pólvora en fábricas reales, los administradores de la fábrica alegaban que eso supondría una segura disminución de la calidad de la pólvora. El fiscal de la Real Hacienda tuvo que parar la ofensiva de los administradores con el argumento de que cuando el Estado hace un contrato, no paga nada hasta «la prueba y examen de la Pólvora que entregaron, conforme a las Ordenanzas... y así quedaría vencido el embarazo que para aceptar la contrata origina este principio de no conocer la bondad, virtud y consistencia de la que proponen fabricar» ${ }^{109}$. A juicio del fiscal, no debía haber ningún debate sobre la supuesta variación en la calidad, solo había que asegurar que el Estado pagase lo que quería comprar con las calidades que había determinado.

Si el Estado tenía posibilidad real de controlar la calidad de los suministros y no era imprescindible para ello producirlos, ¿por qué estaba tan interesado en aplicar el principio de exclusividad? Curiosamente este punto suscitó un extraordinario interés en las reflexiones del ministro de marina Salazar en 1814. Para el mismo ministro el problema estaba en la tendencia política que había mostrado el Estado durante todo el siglo xviII, en su caso la Marina, hacia lo que él llamó la cuestión de las «cosechas propias». Con esta expresión el ministro quería ilustrar lo que a su juicio había sido el principio de exclusividad que había dominado la política de suministros durante el siglo XviII. Para Salazar, con el objetivo de asegurar el abastecimiento de determinados suministros navales, la Marina había controlado directamente la producción. Los ejemplos del cáñamo o la madera son evidentes para el ministro. En el cáñamo, pese a que todos los marinos estaban conformes en la conveniencia de fomentar su cultivo y el consumo del producto nacional, la demanda exclusiva que la Marina pretendió imponer a los productores llevó a que «las cosechas del cáñamo... disminuyeron y la marina volvió a usar en sus consumos los cáñamos extranjeros» ${ }^{110}$. Esta interpretación del ministro debió de estar fundada en un conocimiento de la realidad, porque hemos encontrado suficientes testimonios que muestran que los comisionados de marina encargados de realizar las compras intentaron ir en la dirección de reservar toda la producción en exclusiva para la Armada. Palabras como «embargo», «tasa», "precio fijo» ilustran el tono de unas relaciones entre comisionados y productos cada vez más

109. NúÑEZ ToRRAdo: «Estudios de costes en la renta de la pólvora...», p. 69.

110. Salazar, Juicio crítico... Carta XXIV, p. 127. 
complejas $^{111}$. La pretensión de la Marina de imponerse como único comprador debió de desincentivar a los productores, que literalmente abandonaron esta producción cuando las tesorerías departamentales mostraron que, además, no podían pagarla.

Algo similar debió de ocurrir con la política de exclusividad aplicada al suministro de madera de construcción naval. Pese a que el gran esfuerzo de construcción naval se produjo durante la primera mitad del siglo xviII, entonces no hubo graves carencias de madera ni la necesidad de que el Estado tuviese que intervenir en la organización de operaciones de importación masiva de maderas de fuera de España. La situación cambió drásticamente a partir de la ordenanza de montes de 1748, que pretendía el fomento de plantaciones de árboles para la Armada. El resultado de su aplicación fue todo lo opuesto a lo buscado: el uso restringido de los recursos forestales llevó al enfrentamiento del Estado con los propietarios particulares y pueblos, que además debían encargarse de financiar y mantener la producción y repoblación. Una escalada de pleitos y multas solo sirvió para desincentivar cualquier planteamiento de producción o comercialización, además de deteriorar los beneficios comunitarios de estos recursos ${ }^{112}$. En adelante la falta de madera se hizo cada vez más acuciante, y el Estado se vio obligado abordar como cuestión política la importación masiva de maderas desde el Mediterráneo o el Báltico. El ministro de marina Salazar comentó con detalle este proceso de rápido deterioro en la disponibilidad de madera nacional para la construcción naval, que él atribuye a la decisión política de tener «una cosecha propia», una cosecha exclusiva que impedía la producción y comercialización y que encima debía ser atendida por los propietarios particulares. Para resolver el problema había que, a su juicio, volver a la situación de la primera mitad del siglo XVIII, permitir y hasta favorecer la comercialización de la madera de construcción, con lo que se aseguraba el interés de los propietarios y pueblos en su explotación. Para Salazar el problema no era que faltara el recurso, sino que había una política de suministro errónea. Con un tono irónico concluyó: «hablando con todas veras, tengo para mí como cosa indudable que si por medio de una legislación semejante se intentase también el fomento de las mieses, pronto experimentaríamos los efectos de tan sabias lucubraciones en una hambre general» ${ }^{113}$.

111. Torres Sánchez, R.: «Contractor State and Mercantilism. The Spanish-Navy Hemp, Rigging and Sailcloth Supply Policy in the Second Half of the Eighteenth Century» en Harding y Solbes: The Contractor State..., pp. 317-344.

112. Un buen ejemplo de las consecuencias de la aplicación de la ordenanza de montes en BAudoT Monroy, M.: «Barcos para el Rey. Julián de Arriaga, la madera y la construcción naval (1752-1759)» en García Hurtado, M. R. (ed.): La Armada española en el siglo XViII. Ciencia, hombres y barcos, Madrid, 2012, pp. 297-328. Véase también Aragón Ruano, A.: «La historiografía forestal sobre época moderna en el panorama internacional, español y vasco: una revisión bibliográfica», Vasconia: Cuadernos de historia, 37 (2011), pp. 117-140.

113. Salazar, Juicio crítico... Carta XXVI. De los montes pertenecientes a la marina, p. 33. 


\section{Conclusiones}

Cuando Thompson planteó la trascendencia de la decisión entre administración o asiento como una vía para comprender la naturaleza del Estado nos ofreció una tesis interesante y un material valioso para reflexionar. No obstante, cuando se aplica al caso de la política de suministros militares en el siglo XviI encontramos una realidad diferente. En el trabajo hemos intentado demostrar que la prioridad de los Borbones no fue desarrollar uno de los dos métodos de abastecimiento, ya fuese por razones políticas, ideológicas o de conveniencia con el modelo de Estado que los Borbones estaban construyendo. Más bien creemos que en la política de abastecimiento seguida se impuso una realidad más pragmática, en la que lo prioritario fue garantizar el suministro. El Estado puso por delante de cualquier otra consideración lo que era esencial para su propia constitución: sus fuerzas armadas, su conservación y suministros. Para lograrlo, el Estado fue aplicando a lo largo del siglo xviII todos los medios y métodos disponibles, públicos o privados. Las diferencias y los supuestos límites entre ambos métodos no parece que fueran tan nítidos como tradicionalmente se ha creído, porque el Estado contó con la colaboración, cooperación e identificación con los intereses estatales de los asentistas particulares. No parece que para conseguir los suministros el Estado de los Borbones necesitara enfrentarse u oponerse a los asentistas, ni mucho menos hacerles una cesión de poder y autoridad. Más bien creemos que ocurrió lo contrario, es decir, con la política de suministros militares el Estado de los Borbones logró afianzar su autoridad. Como principal fuente de poder y autoridad, el Estado ofreció a los agentes particulares medios de promoción y diferenciación social. A cambio, los asentistas comprendieron las ventajas de identificarse con los objetivos mercantilistas del Estado, como súbditos nacionales y agentes de la acción política estatal, y aprovecharon la utilidad del principio de exclusividad con el que el Estado pretendió asegurar el abastecimiento, tanto por vías públicas como privadas. La política de suministros militares, en definitiva, fortaleció al Estado y al ejercicio de su autoridad, y con ello el modelo político constitucional de los Borbones. 


\section{Bibliografía}

Aguilar Escobar, A.: Cañones de bronce para el Ejército. Historia de la Real Fundición de Sevilla en el siglo XVIII, Madrid, 2010.

Andrade Muñoz, G. L.: Un mar de intereses. La producción de pertrechos navales en Nueva España, siglo XVIII, México, 2006.

Andújar Castillo, F.: El sonido del dinero. Monarquía, ejército y venalidad en la España del siglo XVIII, Madrid, 2004.

Aragón Ruano, A.: «La historiografía forestal sobre época moderna en el panorama internacional, español y vasco: una revisión bibliográfica», Vasconia: Cuadernos de historia, 37 (2011), pp. 117-140.

Arrieta, G.: Alphabeto y cartilla militar, Cádiz, 1757.

BAKer, N.: Government and Contractors: the British Treasury and War Supplies, 17751783, London, 1971.

Bannerman, G. E.: Merchants and the Military in Eighteenth-Century: British Army Contracts and Domestic Supply, 1739-1763, London, 2008.

Baudot Monroy, M. «Barcos para el Rey. Julián de Arriaga, la madera y la construcción naval (1752-1759)», en GARcía HurTado, M. R. (ed): La Armada española en el siglo XVIII. Ciencia, hombres y barcos, Madrid, 2012, pp. 297-328.

Cabello Vázquez, R.: «Ciencia y guerra en los albores de la química como disciplina: programa francés para la producción de pólvora», en AstigarRAGA, J. y otros: Ilustración, ilustraciones, 2 (2009), pp. 715-734.

Calvo Poyato, J.: «La industria militar española durante la Guerra de Sucesión». Revista de Historia Militar, 33, 66 (1989), pp. 51-71.

Carmona, X.: «Antonio Raimundo Ibáñez, un empresario en el filo de dos épocas», en Ocampo, J.: Empresa y empresarios en el norte de España (siglo XVIII), Trea, pp. 69-90.

Castanedo Galán, J. M.: Guarnizo, un astillero de la Corona, Madrid, 1993.

Conway, S.: Britain, Ireland, \& Continental Europe in the Eighteenth century. Similarities, Connections, Identities, 2011.

Dedieu, J. P.: «Les groupes financiers et industriels au service du roi. Espagne, fin xviredébut xvine siècle», en DuBET, A. y Luis, J. P. (eds.): Les financiers et la construction de l'Etat - France, Espagne (XVIIe-XIXe siècle), Rennes, 2011, pp. 87-104.

Dedieu, J. P.: «Les intermédiaires privés dans les finances royales espagnoles sous Philippe $\mathrm{V}$ et Ferdinand VI», en MeYzIE, V. (ed.): Crédit public, crédit privé et institutions intermédiaires. Monarchie française, monarchie hispanique, XVIe-XVIIIe siècles. Limoges, 2012, pp. 223-239.

DíAz ORdóñez, M.: «El riesgo de contratar con el enemigo. Suministros ingleses para la Armada Real española en el siglo xvIII», Revista de historia naval, 21, $\mathrm{n}^{\circ} 80$ (2003), pp. 65-74.

-: Amarrados al negocio. Reformismo borbónico y suministro de jarcia para la Armada Real (1675-1751), Madrid, 2010.

Dubet, A.: Un estadista francés en la España de los Borbones. Juan Orry y las primeras reformas de Felipe V (1701-1706), Madrid, 2008. 
Espino López, A.: «La historiografía hispana sobre la guerra en la época de los Austrias. Un balance, 1991-2000», Manuscrits, 21 (2003), pp. 161-191.

Esteban Estríngana, A.: «Administración militar y negocio de guerra en los Países Bajos católicos. Siglo XviI», Crespo, A. y Herrero, M. (eds.): España y las 17 Provincias de los Países Bajos. Una revisión historiográfica (XVI-XVIII), I, 2002, pp. 65-100.

— : «El suministro de pólvora en el ejército de Flandes. Sobre la gestión directa y delegada del aprovisionamiento militar (siglo XviI)», en García Hernán, E. y Maffi, D. (eds.): Guerra y Sociedad en la Monarquía Hispánica. Política, Estrategia y Cultura en la Europa Moderna (1500-1700), Madrid, vol. II, 2006, pp. 473-522.

García-Torralba Pérez, E.: La Artillería Naval Española en el siglo XVIII. Su evolución técnica y su recíproca influencia con la arquitectura del buque, Madrid, 2010.

GARNER, G.: «Caméralisme et territoire. Ètat, espace et économie dans le discours économique allemand au xvirIe siècle», Revue du Nord, 85 (octubre-décembre 2003), pp. 729-745.

GLESENER, T.: «La estatalización del reclutamiento de soldados extranjeros en el siglo XVIII», en M.-R. García Hurtado (ed.): Soldados de la Ilustración. El ejército español en el siglo XVIII, A Coruña, 2012, pp. 237-261.

Glete, J.: War and the State in Early Modern Europe. Spain, the Dutch Republic and Sweden as Fiscal-Military States, 1500-1660, London, 2002.

González Enciso, A.: «La promoción industrial en la España Moderna: intervención pública e iniciativa privada», en Rıвот, L. A. y RosA, L. de (eds.), Industria y Época Moderna, Madrid, 2000, pp. 15-46.

—_: «El "Estado económico” en la España del siglo xviII», Memoria y civilización: anuario de historia de la Universidad de Navarra, 6 (2003), pp. 97-139.

—: «Estado militar y empresarios de industrias militares», en González Enciso, A. (ed.): Un Estado Militar. España, 1650-1820, Madrid, 2012, pp. 423-447.

- : «La renovación del asiento de transporte de municiones y armas en 1793 y el protagonismo de una familia navarra», en Memoria y Civilización, 15 (2012), pp. 51-69.

- : «Del contractor state al Estado fabricante. El cambio de propiedad en la fábrica de municiones de Eugui en 1766», en Revista de Historia de la Economía y de la Empresa, VII (2013), pp. 455-480.

Guerrero Elecalde, R.: Las elites vascas y navarras en el gobierno de la Monarquía Borbónica. Redes sociales, carreras y hegemonía en el siglo XVIII (1700-1746), Bilbao, 2012.

IBÁÑez Molina, J.: Rentas Provinciales, administración real y recaudadores en el reino de Felipe V(1700-1739), Granada, Tesis doctoral, microfichas, 1985.

Jiménez Estrella, A.: «Asentistas militares y fraude en torno al abastecimiento de pólvora en el reino de Granada (siglo Xvi)», Investigaciones históricas: Época moderna y contemporánea, 30 (2010), pp. 11-30.

Jiménez Estrella, A. y Andújar Castillo, F. (eds.): Los nervios de la guerra. Estudios sociales sobre el ejército de la Monarquía Hispánica (ss. XVI-XVIII): nuevas perspectivas, Granada, 2007.

Knight, R. y Wilcox, M.: Sustaining the Fleet, 1793-1815. War, the British Navy and the Contractor State, The Boydell Press, 2010. 
Macdonald, J.: Feeding Nelson's Navy. The True Story of Food at Sea in the Georgian Era, London, 2006.

MARTí, R.: Cataluña armería de los Borbones. Las armas y los armeros de Ripoll, Barcelona, Manresa, Igualada...de 1714 a 1794, Barcelona, 2004.

Merino, J. P.: La Armada española en el siglo XVIII, Madrid, 1981.

Mestre Prat De Padua, M.: «La construcción naval de guerra en la España del siglo xviri. El marco legal de los procesos de financiación» en Martínez SHaw, C. (ed.): El derecho y el mar en la España moderna, 1995, pp. 299-322.

Morgan, K.: «Mercantilism and the British empire, 1688-1815», en Winch, D. y P. K. O'Brien (eds.): The Political Economy of British Historical Experience, 1688-1914, Oxford, 2002, pp. 165-191.

Morris, R.: The Foundations of British Maritime Ascendancy. Resources, Logistics and the State, 1755-1815, Cambridge, 2011.

NúÑEz Torrado, M.: «Estudios de costes en la renta de la pólvora de nueva España ante la implantación de un nuevo sistema de gestión (1766-1785)», Revista española de financiación y contabilidad, $\mathrm{n}^{\circ} 111$ (2002), pp. 47-74.

O'Brien, P.: «Taxation for British Mercantilism from the Treaty of Utrecht (1713) to the Peace of Paris (1783)», en Torres Sánchez, R.: War, State and Development..., pp. 295-356.

- : The nature and historical evolution of an exceptional fiscal state and its possible significance for the precocious commercialization and industrialization of the British economy from Cromwell to Nelson», The Economic History Review, 64, 2 (2011), pp. $408-446$.

O’Donnell, H.: «Luis María de Salazar, capitán de navío, ministro de Marina», Cuadernos monográficos del Instituto de Historia y Cultura Naval, n 54, Madrid (2007), pp. 115-128.

Odriozola Oyarbide, M. L.: «La Real Fábrica de anclas de Renteriola: un intento fallido», Boletin de la Real Sociedad Bascongada de Amigos del País, 46, 1-2 (1990), pp. 41-78.

Parrott, D.: The Business of War: Military Enterprise and Military Revolution in Early Modern Europe, Cambridge, 2012.

Phillips, C. R.: Seis galeones para el rey de España: la defensa imperial a principios del s. XVII, Madrid, 1991.

Rodger, N. A. M.: «From the 'military revolution' to the 'fiscal-naval state'», Journal for Maritime Research, 13:2 (2011), pp. 119-128.

Rodríguez Hernández, A. J.: Los tambores de Marte: el reclutamiento en Castilla durante la segunda mitad del siglo XVII (1648-1700), Valladolid, 2011.

SAlazAr, L. M.: Juicio crítico de la marina militar de España dispuesto en cartas de un amigo a otro, Madrid, 1814.

SANZ Ayán, C.: «Negociadores y capitales holandeses en los sistemas de abastecimientos de pertrechos navales de la monarquía hispánica durante el siglo XviI», Hispania, 182 (1992), pp. 915-945. 
Serrano Álvarez, J. M.: El astillero de La Habana y la construcción naval militar (17001750), Madrid, 2008.

Solbes Ferri, S.: «Contracting and Accounting: Spanish Army Expenditure in Wardrobe and the General Treasury Accounts in the Eighteenth Century» en Harding, R. y Solbes, S. (coords.): The Contractor State and Its Implications, 1659-1815, Las Palmas, 2012, pp. 273-293.

Teijeiro de la Rosa, J. M.: La real hacienda militar de Fernando VII: el cuerpo administrativo militar, Madrid, 1995.

Terrón Ponce, J. L.: Ejército y política en la España de Carlos III, Madrid, 1997.

Thompson, I. A. A.: Guerra y decadencia, gobierno y administración en la España de los Austrias, 1560-1620, Barcelona, 1981.

Torres Sánchez, R.: «Cuando las reglas del juego cambian. Mercados y privilegio en el abastecimiento del ejército español en el siglo xvıı», Revista de Historia Moderna, 20 (2002), pp. 487-511.

- : «Producir o comprar, la demanda de la corona española de productos industriales en el siglo xvin»", en Rıвот, L. A. y L. RosA, de: Industria y Época Moderna, Madrid, 2000, pp. 95-131.

— : «El gran negocio de la época, la provisión de víveres al ejército por Francisco Mendinueta (1744-1763)», en Aquerreta, S. (ed.): Francisco Mendinueta: Finanzas y mecenazgo en la España del siglo XVIII, Pamplona, 2002, pp. 101-134.

- : «Velas sin Cañones. La eficacia de las reformas artilleras tras la Guerra de los Siete Años», en Morales Padrón, F. (coord.): Piratería, Corso y Guerra Marítima. XVII Coloquio de Historia Canario-Americana, Las Palmas de Gran Canaria, 2008, pp. 1717-1728.

—-: «Los navarros en la provisión de víveres a la armada española durante el siglo Xvin», en Volver a la «hora navarra». La contribución Navarra a la construcción de la monarquía española en el siglo XVIII, Pamplona, pp. 213-264, 2009.

—-: «Las dificultades de ser financiero extranjero en la España de Carlos III», I Coloquio Internacional "Los extranjeros en la España Moderna», Málaga, 2003, tomo II, pp. 771-780.

- : "The Triumph of the Fiscal-Military State in the Eighteenth Century. War and Mercantilism», en Torres Sánchez, R.: War, State and Development. Fiscal-Military States in the Eighteenth Century, Pamplona, 2007, pp. 13-44.

- : «La política de abastecimiento de cáñamo a la Armada en la segunda mitad del siglo XviII», Revista de Historia Naval, 116 (2012), pp. 47-71.

- : «Los Cinco Gremios Mayores y la provisión de víveres al ejército español en el siglo XviII», Studia Histórica. Edad Moderna, no 34 (2012), pp. 407-432.

- : «In the shade of power. Monopolist entrepreneurs, the State and Spanish Military Victualling in the Eigthteenth Century», en FynN-Paul, J. (ed.): War, Entrepreneurs, and the State, Brill, Leiden, Netherlands, 2013, pp. 17-45. 
— : «Contractor State and Mercantilism. The Spanish-Navy Hemp, Rigging and Sailcloth Supply Policy in the Second Half of the Eighteenth Century», en Harding and Solbes: The Contractor State..., pp. 317-344.

—-: La llave de todos los tesoros. La Tesorería General de Carlos III, Madrid, 2012.

—: El precio de la guerra. El Estado fiscal-militar de Carlos III (1779-1783), Madrid, 2013. Valdez-Bubnov, I.: Poder naval y modernización del Estado: politica de construcción naval española (siglos XVI-XVIII), México, 2011.

Villar Ortiz, C.: La renta de la pólvora en Nueva España (1569-1767), Sevilla, 1988.

Zylberberg, M.: «Des affaires à l'administration: un échec de François Cabarrus», en Vincent, B. y Dedieu, J.-P.: L'Espagne, l'Etat, les Lumières : mélanges en l'bonneur de Didier Ozanam, 2004.

Zylberberg, M.: Une si douce domination. Les milieux d'affaires français et l'Espagne vers 1780-1808, París, 1993. 